\title{
Variabilidade Climática - processos físicos e dinâmicos nos oceanos e atmosfera
}

\author{
Maria Elisa Siqueira Silva ${ }^{1}$ \\ Carlos Batista Silva ${ }^{2}$
}

\begin{abstract}
Resumo: O clima apresenta grande importância nos estudos científicos devido à sua determinação nos modos de vida do planeta e mesmo na definição das condições essenciais para a própria vida. A demonstração de teorias e processos climáticos físicos e dinâmicos, evidenciando a complexidade a eles inerente, motivou a elaboração da presente revisão. Neste artigo são evidenciados os padrões de oscilação climática que ocorrem nos oceanos atrelados ao comportamento da atmosfera. Destaca-se a importância de fontes de calor no Oceano Pacífico como responsáveis por padrões distintos do escoamento na atmosfera. Dentre as oscilações evidenciadas estão os padrões do Pacífico e Atlântico norte, do Pacífico e Atlântico Sul, as oscilações do Atlântico Norte e da Antártica. Faz-se referência ainda aos impactos em temperatura do ar e precipitação sobre a América do Sul.
\end{abstract}

Palavras-Chave: variabilidade climática; fontes de calor no oceano; teleconexões.

\section{Climatic Variability - physical and dynamical processes on ocean and atmosphere}

\begin{abstract}
Climate presents significant importance on scientific studies due to its influence on life style and even on essential conditions to life. A presentation of climatic theories and the related physical and dynamical processes, underlying the inherent complexity to them, has motivated this revision. In this article, we put in evidence oceanic and climatic oscillation patterns that occur in association to the behavior of the atmosphere. We bring up the importance of heat sources over the Pacific Ocean that are responsible for different patterns (PNA), the South Pacific patterns (PSA), the North Atlantic (NAO) and the Antarctic Oscillation (SAM). The impact on air temperature and precipitation over South America due to the mentioned oscillations is also put in evidence.
\end{abstract}

Keywords: climatic variability; oceanic heat sources; teleconnections.

\section{INTRODUÇÃO}

O clima terrestre é uma poderosa variável do sistema natural. É um dos elementos naturais com capacidade de influenciar a vida no planeta, a distribuição espacial das florestas úmidas, tropicais, temperadas e áreas desérticas, além de contribuir com papéis essenciais na organização do espaço geográfico, como em atividades desenvolvidas nos espaços agrários, vinculadas à geração de energia elétrica, associadas ao desenvolvimento industrial, aos

\footnotetext{
${ }^{1}$ Bacharel em Meteorologia pela Universidade de São Paulo, mestre em Meteorologia pela Universidade de São Paulo e doutora em Meteorologia pelo Instituto Nacional de Pesquisas Espaciais. Professora do Departamento de Geografia da Universidade de São Paulo. Email: elisasiq@usp.br

${ }^{2}$ Licenciatura Plena e Bacharelado em Geografia pela Universidade Estadual Paulista (UNESP), campus de Presidente Prudente/SP e mestre em Geografia (Geografia Física) pela Universidade de São Paulo (USP). E-mail: krlosbatist@gmail.com
} 
meios de transportes e na qualidade dos ambientes e processos de ocupação social (Monteiro, 1976).

Considerando a concepção sistêmica, vários autores que escreveram sobre o clima no contexto da ciência geográfica (e.g., Monteiro, 1971; Conti, 1975; Tarifa, 1975; Zavatini, 1983; Sant'Anna Neto, 1990; Brigatti, 2008) já sugeriram que o clima, e seus impactos, requererem uma análise muito mais sistêmica (Berthand; 1972; Sochava, 1977; Bolos, 1981; Beroutchachvilie e Panareda 1977; Beroutchachvilie e Mathieu, 1977 e Monteiro; 2000), de tal forma que o entrelaçamento dos fatores climáticos condicionantes e suas repercussões no espaço geográfico seja evidenciada.

No contexto geográfico, o clima interfere na dinâmica da superfície terrestre devido à sua irregularidade e à sua intrínseca e relativamente baixa previsibilidade atual. Os desvios climáticos em torno da média climática regional constituem sua variabilidade. A variabilidade climática observada em qualquer ponto do globo terrestre induz à curiosidade acerca dos processos físico-dinâmicos que a estabelece. Assim como os sistemas atmosféricos da escala sinótica (e local) definem o estado de tempo de uma determinada localidade, sistemas climáticos específicos determinam padrões climáticos para uma determinada região do globo. Este artigo pretende rever, ao menos em parte, importantes processos oceânicos e atmosféricos que contribuem para a definição do clima, e/ou da variabilidade climática, dando maior ênfase àqueles que influenciam mais diretamente a América do Sul.

Dentre os elementos climáticos que influenciam o comportamento atmosférico, a camada superficial dos oceanos tem papel importante. A temperatura da superfície do mar é usualmente considerada uma variável que caracteriza a camada superficial oceânica, despertando grande atenção e motivação em sua investigação. A associação entre a variabilidade climática da atmosfera e as condições oceânicas é justificada pela alta capacidade térmica da água (oceanos) e pela grande importância dos processos físicos de interação com a atmosfera (e.g., Aceituno, 1989; Tremberth, 1997; Coelho, 2001). A lenta taxa de variação da temperatura dos oceanos associa-se com a variabilidade atmosférica na escala climática, com ganhos e perdas de calor na atmosfera.

Com base nestas considerações, sugere-se que os oceanos assumam o papel de "modulador" do clima global. Desta forma, pode-se supor que a variação da temperatura da superfície do mar (TSM) assuma o papel de forçante atmosférica (e.g., Walker, 1924; 
Bjerknes, 1969; Hoskins e Karoly, 1981; Müller e Ambrizzi, 2007), capaz de alterar o padrão de escoamento atmosférico, observado nos campos de pressão do ar e vento, e os padrões de propagação das ondas de Rossby (padrões de teleconexões atmosféricas). Os diferentes padrões de propagação de ondas na atmosfera são estabelecidos parcialmente pelos diferentes padrões de aquecimento da superfície oceânica, impactando de distintas formas, áreas remotas do globo.

A preocupação em se incorporar processos atmosféricos fisicos e dinâmicos nos estudos sobre o clima não é algo recente. Desde as contribuições da escola norueguesa de meteorologia com a publicação do livro On the dynamics of the circular vortex with applications to the atmosphere and to the atmospheric vortex and wave motion, de Bjerknes, em 1921, seguidas das contribuições propostas pelos artigos de Walker (1924), Walker e Bliss (1932) e Rossby (1938), novas concepções sobre a atuação de processos fisicos e dinâmicos na atmosfera têm tornado mais complexas as explicações sobre o sistema climático, aprofundando o seu conhecimento.

Uma das principais observações feitas pela escola norueguesa de meteorologia e pelos trabalhos de Bjerknes (1921), de Walker e Bliss (1932) e de Lorenz (1963) foi indicar que a atmosfera constituía-se em um fluido dinâmico, marcado por aspectos não-lineares (Lorenz, 1963). A partir deste momento, todas as pesquisas que se dedicaram aos estudos da atmosfera tiveram a oportunidade de interpretá-la como um fluido dinâmico, um todo integrado, com trocas de energia em suas várias escalas (tal como em qualquer fluído dinâmico), superando as antigas concepções climáticas de Julius von Hann (1883), as quais tratava a atmosfera como algo estático.

Um dos exemplos mais atuais desta complexidade atmosférica pode ser fornecido pela teoria das teleconexões e dos papéis de forçantes nos campos climáticos, como destacado por Hoskins e Karoly (1981). Além de aprofundar a compreensão do escoamento da atmosfera em escalas maiores, as contribuições de Walker (1924) e de Walker e Bliss (1932) já haviam ressaltado a importância da interação oceano-atmosfera dentro do sistema climático integrado e dinâmico.

Com base nas duas últimas contribuições citadas, diversos estudos mostraram a preocupação em compreender a sucessão das condições de tempo nos lugares como produto de interações no espaço tri-dimensional. Dentre as principais contribuições, as que definiram anomalias de temperatura da superfície do mar e cadeias montanhosas como 
forçantes do sistema climático, como no estudo de Hoskins e Karoly (1981), foram as que mais ganharam repercussões e que despertaram a atenção em estudos científicos.

De fato, inúmeros trabalhos mostraram algumas das repercussões climáticas, em diversas regiões do globo desencadeadas pelas alterações da temperatura da superficie do mar. Dentre eles, destacam-se os trabalhos dedicados em mostrar as interferências diretas e indiretas da atmosfera no comportamento temporal das chuvas na América do Sul, como os de Aceituno $(1987 ; 1988)$ e o de Coelho (2001), além daqueles que observaram o comportamento dos campos fluviais de rios da América do Sul em associação com a TSM, como os estudos de Santos e Pereira Filho (2003), Gomes Filho et al. (2000), Cardoso et al. (2004), Cardoso e Dias (2002) e Cardoso (2005). Outros tantos estudos procuraram relacionar o papel das anomalias de TSM no espaço agrário, destacando a variabilidade de safras agrícolas, como mostraram Barbano et al. (2001), Berlato et al. (2005) e Carmona et al. (2002).

As anomalias da temperatura na superfície dos oceanos estão, em geral, associadas a anomalias nos campos de pressão atmosférica e constituem variáveis que indicam padrões anômalos locais que podem se propagar para áreas remotas. Desta forma, a caracterização de padrões climáticos pode ser expressa em termos de índices elaborados para áreas específicas e estimados, muitas vezes, pela diferença entre anomalias de TSM e de pressão atmosférica entre áreas que apresentam comportamentos distintos. Os destaques atribuídos aos efeitos das oscilações de pressão atmosférica e da temperatura da superfície dos oceanos na atmosfera constituem um tema debatido desde a década de 1920, com os trabalhos de Walker $(1924 ; 1928)$, assim como as repercussões nos campos atmosféricos em consequência das alterações na TSM.

As explicações dos processos físicos e dinâmicos pelos quais anomalias da TSM e de pressão atmosférica modificam remotamente os padrões de precipitação e temperatura podem ser mais bem apreendidas através dos conhecimentos contidos nos trabalhos clássicos de Walker (1924), Walker e Bliss (1932), Bjerknes (1969), Hoskins e Karoly (1981), Wallace e Gutzler (1981) e, Karoly (1989). Todas estas pesquisas apresentam um caráter básico para a compreensão mais aprofundada de variabilidade climática em contexto global.

\section{Especificidades da variabilidade climática e da atmosfera}


Com a característica de um fluido dinâmico, a atmosfera é marcada pelo desenvolvimento ininterrupto de perturbações, desenvolvimento assegurado pelas próprias características térmicas, como ressaltou Lorenz (1963), em estudos experimentais. Além desta característica geral, muitas das vezes a atmosfera sofre os efeitos de forcantes específicas, térmica ou orográfica, tal como indicaram Hoskins e Karoly (1981). As perturbações daí resultantes tornam-se ainda mais evidentes e podem dar origem a fenômenos atmosféricos com características particulares, como, por exemplos, os bloqueios, estudados por Rex (1950a), Trenberth (1986), Rivas-Kainay e Merkine (1981) e Berbery e Nunez (1989). Além de fenômenos específicos como os bloqueios (característicos da escala sinótica), sabe-se que a indução de forçantes na atmosfera pode ainda se repercutir direta e indiretamente na variabilidade dos principais padrões da circulação de grande escala, como destacou Ambrizzi (2003), detrminando a produção de trens de ondas que se originam em uma área específica e que são capazes de promover alterações na variabilidade atmosférica em áreas remotas, processo conhecido como teleconexão atmosférica (Hoskins e Karoly, 1981). A propagação de trens de ondas na alta troposfera do hemisfério norte, devido a forcantes orográficas (Himalaia e Montanhas Rochosas) é ilustrada na Figura 1.

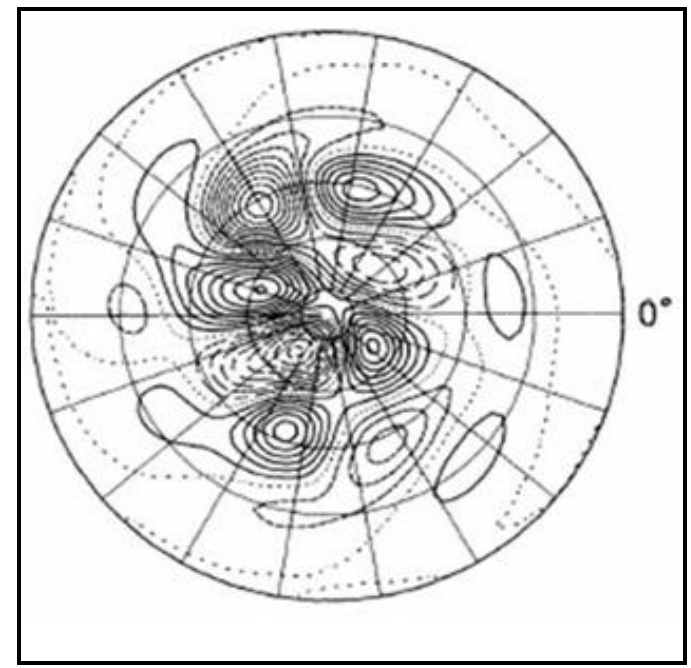

Figura 1 Campo da perturbação da altura geopotencial em 300 hPa no hemisfério norte, forçado por cadeias orográficas. Valores positivos e negativos das anomalias de geopotencial nesta altitude evidenciam a propagação de ondas em torno da região polar. Fonte: Hoskins e Karoly (1981).

Os bloqueios podem ser definidos como anomalias persistentes de alta pressão, com deslocamento meridional característico em relação às trajetórias normais do escoamento atmosférico (Berbery e Nunez, 1989) e, as teleconexões, como modos preferenciais da 
variabilidade de baixa frequência, podendo apresentar padrões em escala planetária, cobrindo áreas oceânicas e continentais, como destacou Ambrizzi (2003). Os trens de ondas gerados pela indução de forçantes térmicas e orográficas podem modificar os padrões atmosféricos e produzir persistentes anomalias de pressão em grande escala capazes de cobrir vastas regiões continentais, tal como destacado por Cavancanti e Ambrizzi (2009).

As primeiras observações sobre teleconexão atmosférica foram realizadas pelo professor de meteorologia da Universidade de Uppsala, na Suécia, Hugo Hildebrand Hildebrandson, em 1897, e por Lockyer e Lockyer (1904) apud Cavalcanti e Ambrizzi (2009). Mesmo sendo conhecida desde o final do século XIX, somente a partir das primeiras décadas do seculo XX é que surgiram as primeiras grandes contribuições científicas sobre padrões de teleconexões atmosféricas, com o trabalho de Walker (1924) e de Walker e Bliss (1932). Walker (1924) identificou três oscilações climáticas distintas: oscilações do Pacífico, do Atlântico Norte e, oscilação sul. Walker e Bliss (1932) identificaram repercussões nos campos termopluviométricos de áreas remotas atreladas à variabilidade das oscilações identificadas por Walker (1924). Os resultados encontrados nestes estudos evidenciaram as modificações nos padrões de circulação atmosférica global, os padrões de propagação de ondas de Rossby e os preceitos das teleconexões atmosféricas, as quais podem ser, didaticamente, apresentadas pelos estudos conceituais realizados por Müller e Ambrizzi (2007).

Para Müller e Ambrizzi (2007), a indução de uma forçante térmica no Indico Tropical com o uso de modelos numéricos foi capaz de gerar um duplo trem de ondas, propagando-se em associação aos jatos polar e subtropical no hemisfério sul e, unindo-se mais adiante, após cruzar a barreira orográfica da cadeia montanhosa andina. Segundo os autores, a unificação dos trens de ondas contribuiu para alteração do padrão de circulação atmosférica do sul da América do Sul, forçando o surgimento de fenômenos extremos de advecção de ar frio, como a ocorrência de geadas na região dos pampas argentinos. A configuração espacial deste duplo trem de ondas é ilustrada na Figura 2. Os resultados deste trabalho exemplificam preceitos teóricos de indução e propagação das ondas de Rossby e seus efeitos no clima em regiões remotas, o que foi também evidenciado no trabalho de Hoskins e Ambrizzi (1993). O diagrama conceitual de Müller e Ambrizzi (2007) permite compreender o funcionamento físico e dinâmico das teleconexões atmosféricas no hemisfério sul associadas à propagação de ondas de Rossby no Pacífico e aos jatos subtropical e polar. 


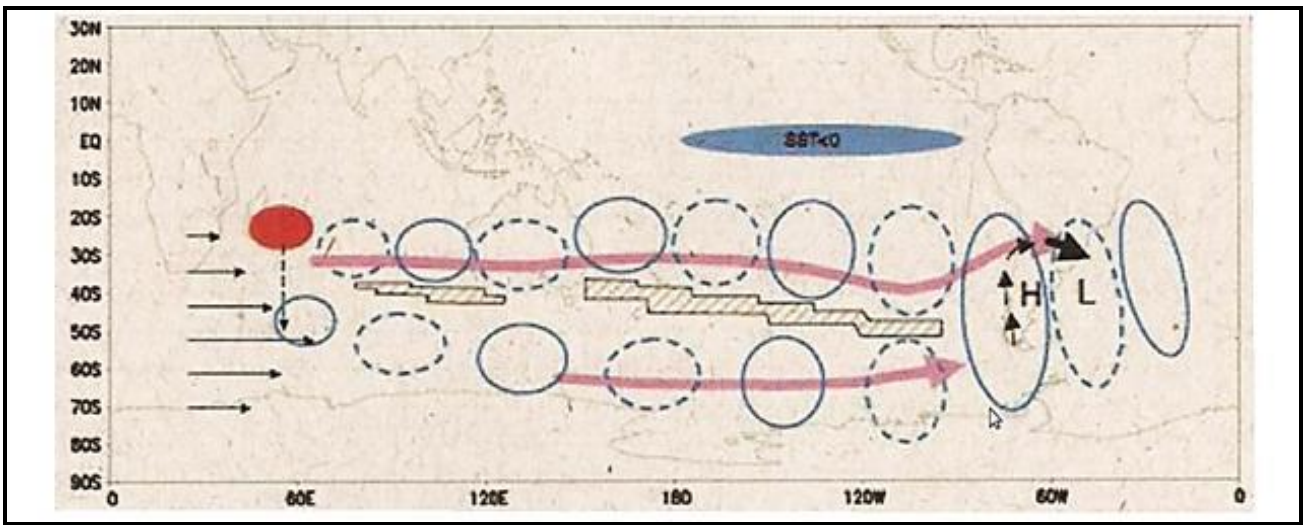

Figura 2 Diagrama conceitual sobre os mecanismos físicos que podem favorecer a ocorrência da alta frequência de geadas generalizadas sobre o oeste dos pampas argentinos. Fonte: Müller e Ambrizzi (2007).

Frederiksen e Webster (1988) evidenciaram a existência de três grandes padrões globais de teleconexões atmosféricas. O primeiro padrão está associado à ocorrência de anomalias de aquecimento tropical e sua influência em latitudes mais altas, conhecida como teleconexão dos trópicos para os extratrópicos, de acordo com Bjerknes (1969), Horel e Wallace (1981), Wallace e Gutzler (1981), Koskins e Karoly (1981) e Karoly (1989). O segundo padrão está associado a influência de eventos extratropicais nos trópicos, teleconexão extratropical para os trópicos, e o terceiro, aos modos lentos de propagação de ondas quase estacionárias de Kelvin, em grande escala. Este último padrão garante a comunicação dos trópicos com os próprios trópicos, tal como discutem Lau e Philips 1986).

Destes três padrões de teleconexões atmosféricas, destaca-se especialmente o primeiro padrão (teleconexão dos trópicos para as extratrópicos) por estar associado a inúmeras contribuições científicas (e.g., Walker, 1924; Troup, 1965; Bjerknes, 1969) e por ter havido elaborações conceituais de modelos hipotéticos para exemplificar seu funcionamento, como destacaram Wallace e Gutzler (1981), Horel e Wallace (1981) e Karoly (1989). As contribuições destes três últimos trabalhos são merecedoras de destaque neste contexto por terem fomentado o debate científico a respeito da dinâmica da variabilidade climática, atrelando os papéis de forçantes térmicas em áreas equatoriais às anomalias nos campos climáticos.

A contribuição de Horel e Wallace (1981) sugere que as anomalias de TSM observadas na bacia do Pacífico Equatorial, durante os anos de El Niño, foram capazes de produzir padrões atmosféricos específicos de anomalias de geopotencial na alta troposfera, os quais ligavam a região de latitudes baixas às áreas das latitudes médias e altas no hemisfério norte, como ilustrado na Figura 3. Muito embora este padrão tenha sido observado por Horel e Wallace (1981) e Wallace e Gutzler (1981), o mesmo já havia sido identificado em décadas anteriores 
por Namias (1951) e Bjerknes (1969). Tal padrão ficou conhecido como Pacific North American (PNA) (Figura 3).

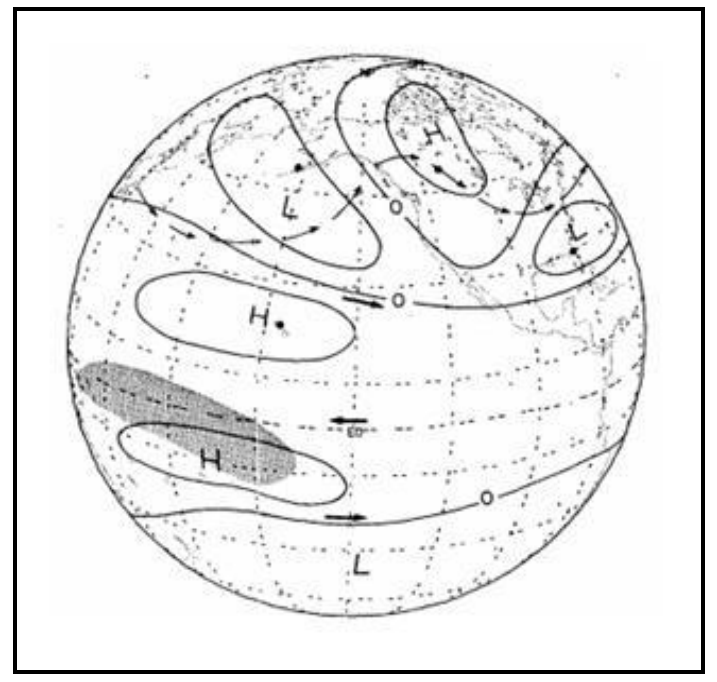

Figura 3 Ilustração esquemática do padrão hipotético de anomalias de altura geopotencial (linhas sólidas) durante o inverno do HN, durante episódios de aquecimento do Pacífico tropical. As setas escuras refletem o reforço dos jatos subtropicais em ambos hemisférios, ficando mais fortes e próximos do equador durante episódios quentes. As setas no HN mostram um tipo leve de meandros troposféricos, com um tipo de anomalia pronunciada sobre o Pacífico central e a oeste do Canadá. As áreas sombreadas indicam regiões com nuvens cirros e chuva. Fonte: Horel e Wallace (1981)

A ilustração anterior evidencia que em períodos de anomalias positivas de TSM na região equatorial do Pacífico surge um duplo anticiclone na alta troposfera nos subtrópicos, nos dois hemisférios, associados à convecção equatorial anômala sobre as águas do Pacífico Equatorial. A compreensão física deste fenômeno mostra uma quasi-independência entre os movimentos superiores e inferiores nos trópicos, em períodos de Niño, como evidenciou Charney (1963 e 1969). Além disto, a ilustração mostra que ao norte e a leste da fonte de calor tropical surge um aparente trem de ondas que se estende aos extratrópicos no hemisfério de inverno (hemisfério norte, neste caso). No hemisfério norte, a intensificação do jato subtropical no Pacífico condiciona um ligeiro deslocamento para sul, em relação à sua posição habitual, e um trem de ondas anômalo que cruza o Pacífico Norte em direção à América do Norte. A propagação de ondas em um sistema alternado de altas e baixas pressões, modifica a circulação do hemisfério norte dando origem a um escoamento com regiões de cristas e cavados, como mostrado na Figura 3. Nas áreas de cristas, preferencialmente, o ar mais quente das regiões dos trópicos pode atingir latitudes mais altas - proporcionando aumento de temperatura acima da média para latitudes mais altas da costa oeste do Canadá - e, preferencialmente nas áreas de cavado, o ar mais frio das 
regiões polares pode atingir latitudes mais baixas - proporcionando uma anomalia negativa de temperatura nas latitudes mais baixas da costa leste dos Estados Unidos.

O modelo sugerido por Horel e Wallace (1981) para descrever os padrões de teleconexão para o hemisfério norte foi ampliado por Karoly (1989), com a descrição de padrões atmosféricos para o hemisfério sul. Na Figura 4 estão ilustrados os trens de ondas obtidos por Karoly (1989), para o período de inverno nos dois hemisferios. O modelo conceitual proposto por Karoly (1989) foi estruturado com base na média do padrão atmosférico de altura geopotencial em $200 \mathrm{hPa}$ para períodos de ENSO (1950-1979) e em três eventos de ENSO ocorridos em 1972, 1973-1976 e 1982-1983. A composição média sazonal e as respectivas anomalias foram obtidas para as estações de verão e inverno, para os três períodos de ENSO considerados.
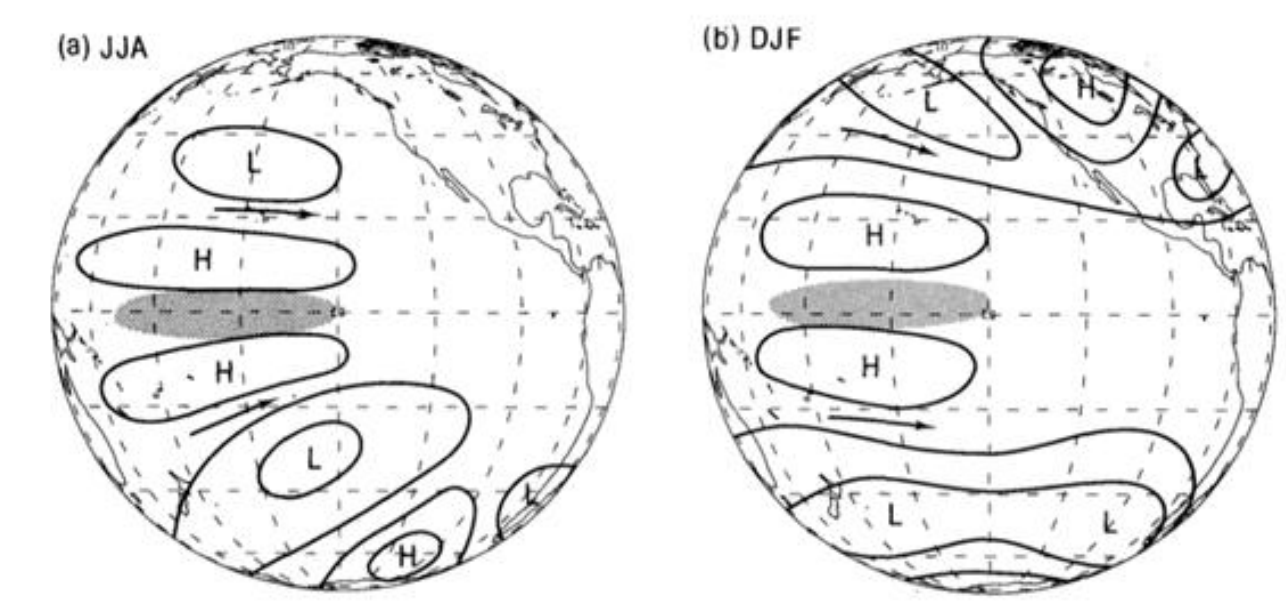

Figura 4 Ilustração esquemática do padrão de anomalias de altura geopotencial na alta troposfera sobre o Oceano Pacífico durante (a) o período de desenvolvimento de um evento de El Niño no inverno do HS (JJA) e (b) estágio de desenvolvimento de um evento de El Niño no verão do HS (DJF). As regiões sombreadas indicam a convecção anômala sobre o Pacífico equatorial central e as setas, as anomalias dos jatos. Fonte: Karoly (1989).

O modelo hipotético sugerido por Karoly (1989) (Figura 4) indica que durante o inverno do hemisfério sul, um padrão de trem de ondas estende-se sobre o Pacífico Sul, indo em direção à América do Sul. Este padrão de trem de ondas é bastante variável em amplitude e localização e apresenta configurações distintas para cada evento de Niño, embora seja mais estável sobre o setor subtropical do Pacífico. Durante o verão do hemisfério sul, as anomalias da circulação atmosférica são mais zonalmente simétricas nas latitudes altas e médias, com um grande prolongamento de anomalias negativas de altura geopotencial. Além disso, nota-se uma modificação do posicionamento dos jatos subtropicais (Karoly, 
1989). As anomalias de circulação durante o verão do hemisfério sul são espacialmente mais estáveis do que no inverno, apresentando anomalias similares nos subtrópicos e em latitudes médias. A ilustração do padrão proposto por Karoly (1989) (Figura 4) permite identificar que durante o período de inverno austral, as anomalias com padrão de dipolo apresentam-se com configurações mais bem definidas.

Este padrão observado por Karoly (1989), já tinha sido identificado anos antes por Mo e Ghil (1987) e Szeredi e Karoly (1987a;b), os quais o denominaram de padrão Pacific South American (PSA). Nas contribuições de Mo e Ghil (1987) é possivel identificar, pela aplicação de análises de componentes principais aos dados de geopotencial em $200 \mathrm{hPa}$, um padrão espacial de troca sequencial de sinal nas anomalias de geopotencial na atmosfera no primeiro modo. Este padrões observados configuraram-se como trens de ondas com grandes amplitudes, com propagação desde a porção central do Pacífico até o cone sul da América do Sul (PSA). Nas contribuições de Szeredi e Karoly (1987a;b), entretanto, com a consideração de um conjunto maior de dados de estação de superfície (temperatura e vento) do que o considerado por Mo e Ghil (1987), foi observado não apenas um padrão sequencial de repetições espaciais de anomalias com sinais contrários, mas sim dois padrões. A este novo padrão foi dado o nome de PSA2, tal como ilustrado na Figura 5. As principais diferenças entre o primeiro e segundo padrões do hemisfério sul, PSA1 e PSA2, estão associadas às variações nas escalas de tempo. Os estudos de Szeredi e Karoly (1987a,b) permitiram a identificação de que o padrão PSA1 apresentou uma variação associada à escala interanual e o padrão PSA2, à escala quasi-bianual. Ambos associados a eventos ENSO, conforme os autores.
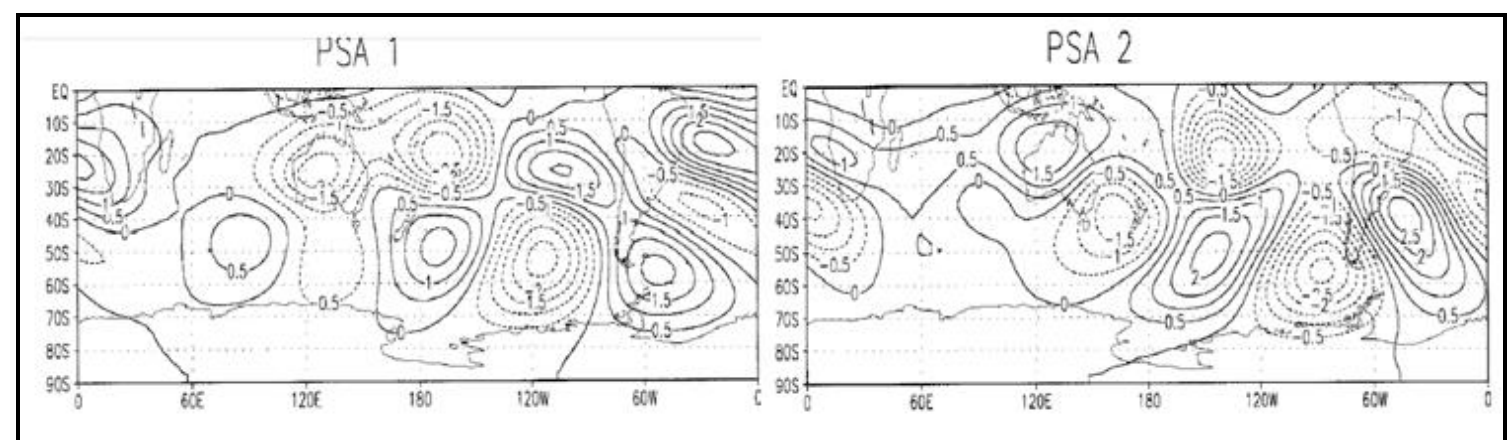

Figura 5 Os dois primeiros modos espaciais da análise de componentes principais, PSA1 e PSA2, respectivamente, aplicada à altura geopotencial (mgp) em $200 \mathrm{hPa}$. Os modos espaciais da ACP foram normalizados. Os intervalos de contornos são iguais a 0,5 (unidade adimensional). As análises foram realizadas para o período de inverno de 1973 a 1995, no hemisfério sul. Fonte: Mo e Higgins (1998)

O padrão PSA1 relaciona-se diretamente com as anomalias de TSM na porção central e oriental do Pacífico, segundo Mo e Nogues-Paegle (2001). Na escala de tempo interanual, o 
PSA1 aparece como uma resposta aos eventos ENOS. Portanto, sugere-se que os padrões de precipitação relacionados ao PSA1 estejam associados a composições relacionadas a eventos ENOS. A fase positiva do PSA1 está associada a um dipolo de chuva entre as regiões norte da América Central e sul da América do Norte e, o norte da América do Norte. Durante o verão, apresenta diminuição dos totais pluviais ao longo do norte do Brasil e o aumento da chuva ao longo do sul-sudeste dos Estados Unidos, como indicado na Figura 6. Por outro lado, o padrão PSA2 associa-se à componente quasi-bianual dos eventos ENSO, com periodicidade entre 22 e 28 meses. Os padrões PSA1 e PSA2 desencadeiam impactos distintos e substanciais na atmosfera, redundando em diferentes controles sobre as anomalias de precipitação na América do Sul. Estes padrões apresentam-se vinculados entre si tanto na escala interanual quanto na decadal, como explicam Mo e Nogues-Paegle (2001).

Os modos preferenciais de variabilidade da atmosfera, como os padrões PNA e PSA, relacionados aos padrões de teleconexões, além de estarem associados a forçantes térmicas, reforçam a necessidade de compreensão dos processos dinâmicos da atmosfera e o entendimento de sua complexidade. A relevância dos estudos sobre as teleconexões atmosféricas se dá pela evidente alteração do padrão climático regional e pelas contribuições que sua compreensão pode proporcionar aos estudos de variabilidade climática.

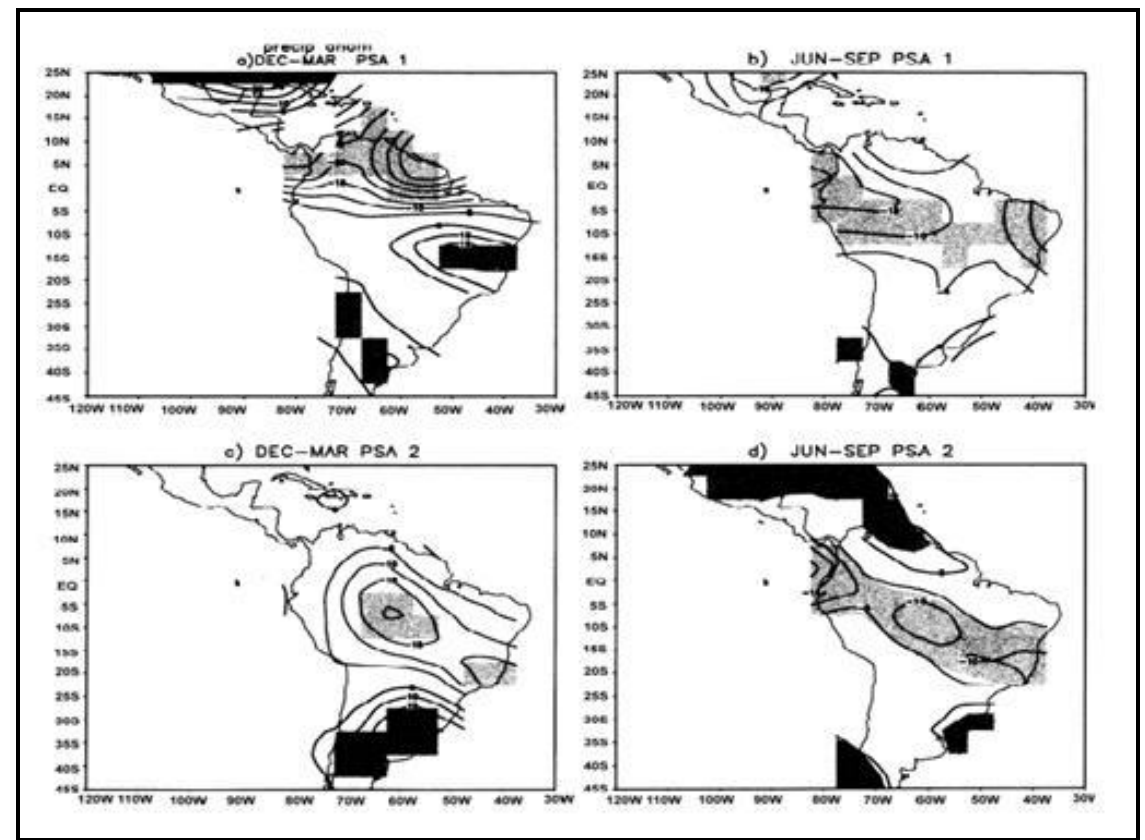

Figura 6 (a) Média da diferença de chuva entre as fases positiva e negativa dos eventos PSA1 para dezembromarço. A isolinha está em mm. Contornos com valores nulos foram omitidos. Áreas onde os valores positivos (negativos) são estatisticamente significativos (acima de 95\%) foram sombreadas com cinza (claro); (b) idem a (a), mas para o período de junho-setembro, (c) idem a (a), mas para os eventos PSA2 e; (d) idem a (b), mas para os eventos de PSA2. Fonte: Mo e Nogues-Paegle (2001) 
Silva (2012) estudou as diferenças de propagação de ondas de Rossby em condições secas e úmidas para a região central da América do Sul, região do Pantanal. Observou que intensas anomalias de TSM na bacia do Pacífico Equatorial Sul foram capazes de perturbar a atmosfera e gerar padrões de trens de ondas que se propagaram em direção à América do Sul, interferindo nos campos atmosféricos na escala climática. As anomalias de TSM contribuíram para a formação de anomalias na alta troposfera, que foram identificadas pelas anomalias positivas e negativas da função de corrente em $250 \mathrm{hPa}$, sobre a região equatorial do Pacífico Sul (Figura 7). A propagação destas anomalias em direção à América do Sul perturbou a atmosfera na porção central do continente sulamericano (Figura 7).

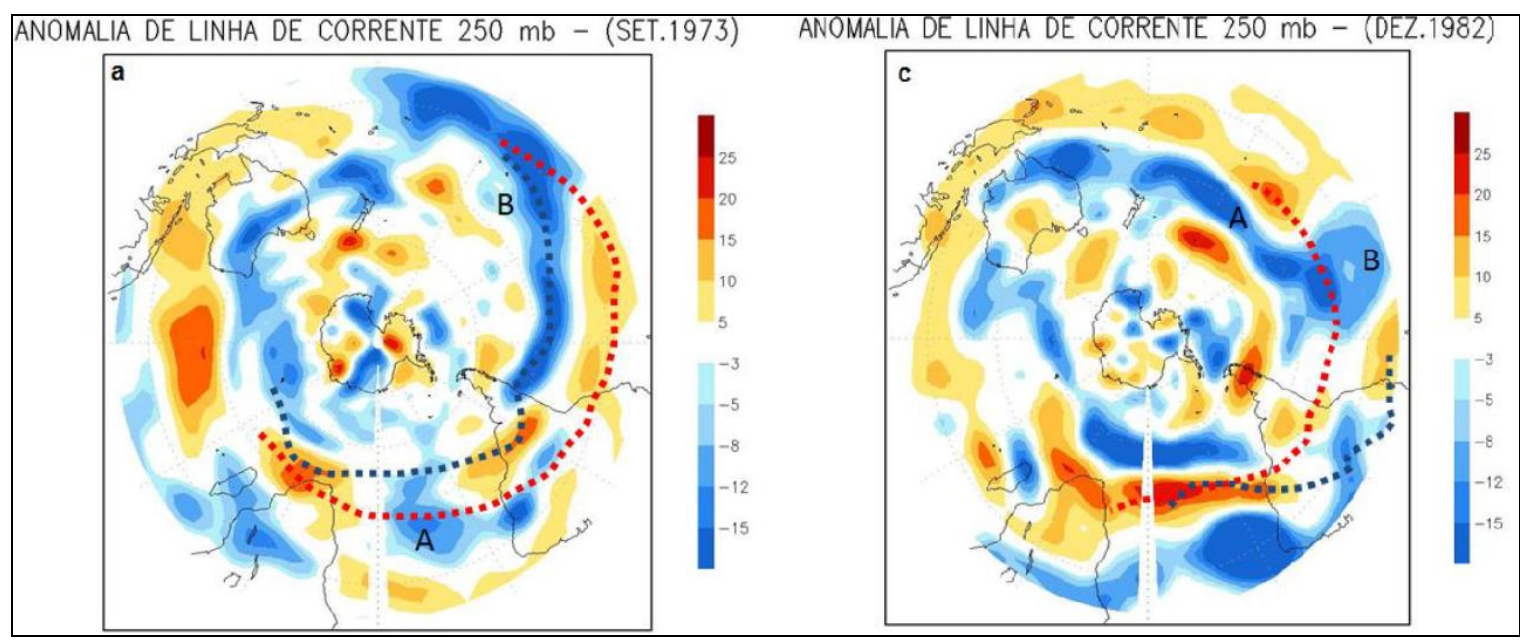

Figura 7 Anomalia mensal da função de corrente, em 250 hPa, em anos com anomalias positivas de TSM no Pacífico Equatorial (anos de El Niño) em localidades distintas, para (a) setembro de 1973 (b) dezembro de 1982. O valor da função de corrente está multiplicado por $10^{6}$. A trajetória dos trens de onda A e B foram definidas com base nas observações dos padrões ciclônicos e anticiclônicos na alta troposfera. Fonte: Silva, C. B. (2012)

A formação de anomalias específicas do escoamento atmosférico em altos níveis condicionou a intensificação de movimentos convergentes e divergentes do ar em baixos níveis, determinando condições de um padrão climático mais seco e mais chuvoso nos respectivos anos sobre o Pantanal.

\section{A complexidade dos índices climáticos no contexto da variabilidade atmosférica}

O sistema oceano-atmosfera apresenta padrões espaciais de oscilação, ou variabilidade, caracterizados especialmente pela alternância do sinal de anomalias da TSM ou pressão ao nível do mar. Tais oscilações podem também ser expressas por meio de índices climáticos que pretendem apresentar parte importante da oscilação observada. Em parte, os índices 
são úteis devido à simplificação da informação climática. Por outro lado, a simplificação inerente ao cálculo do índice climático despreza características espaciais e temporais eventualmente importantes associadas à oscilação considerada. Alguns índices climáticos foram criados para facilitar o diagnóstico de ocorrência de fenômenos climáticos. A associação entre os valores dos índices climáticos e a variabilidade climática remota está associada às explicações teóricas sobre a dinâmica da atmosfera, como destacado por Bjerknes (1921), Walker (1924), Rossby (1938), e Bergeron (1939). A simples associação entre a variabilidade das condições climáticas em regiões distantes não permite entender os processos responsáveis pelas teleconexões atmosféricas e, como evidenciam Murakami e Unninayar (1977) e Webster e Holton (1981), a existência de "dutos" de comunicação atmosférica interhemisférica.

É muito provável que a fonte mais expressiva de variabilidade interanual nos trópicos seja o ENSO (McPhaden, 2002). Este fenômeno é caracterizado por um processo acoplado entre o oceano e a atmosfera e é causado pela recorrente distribuição de calor e momento entre os setores leste e oeste do Pacífico Equatorial (atmosfera e oceano), como notificou McPhaden (2002). A distribuição zonal do aquecimento superficial entre áreas continentais e oceânicas produz um padrão de circulação leste-oeste conhecida como Circulação de Walker (Walker e Bliss, 1932), ilustrada na Figura 8. Tal circulação é caracterizada por forte convergência do ar em baixos níveis troposféricos sobre o continente marítimo, Indonésia e sudeste asiático, devido ao intenso aquecimento diabático da região. A ocorrência do fenômeno ENOS perturba a Circulação de Walker e dispara grandes deslocamentos nos padrões de chuva e convecção profunda, quebrando circulações atmosféricas e climáticas em torno do globo, como evidenciaram MacPhaden (2002), Philander (1990) e Trenberth (1997).

As células de circulação zonal existem devido aos fortes gradientes leste-oeste da temperatura da superfície do mar e da estrutura térmica subjacente dos oceanos Pacífico e Atlântico, assim como pelo aquecimento das regiões tropicais continentais. As regiões associadas às células zonais com valores pluviométricos mais expressivos ocorrem sobre os oceanos. A liberação de calor latente durante os períodos de fortes tempestades intensifica o movimento ascendente e a convergência do ar de leste e oeste, contribuindo, assim, para a estruturação de uma forte célula ao longo do equador. Movimentos subsidentes correspondentes ocorrem sobre o setor leste frio do Pacífico (Figura 8). 


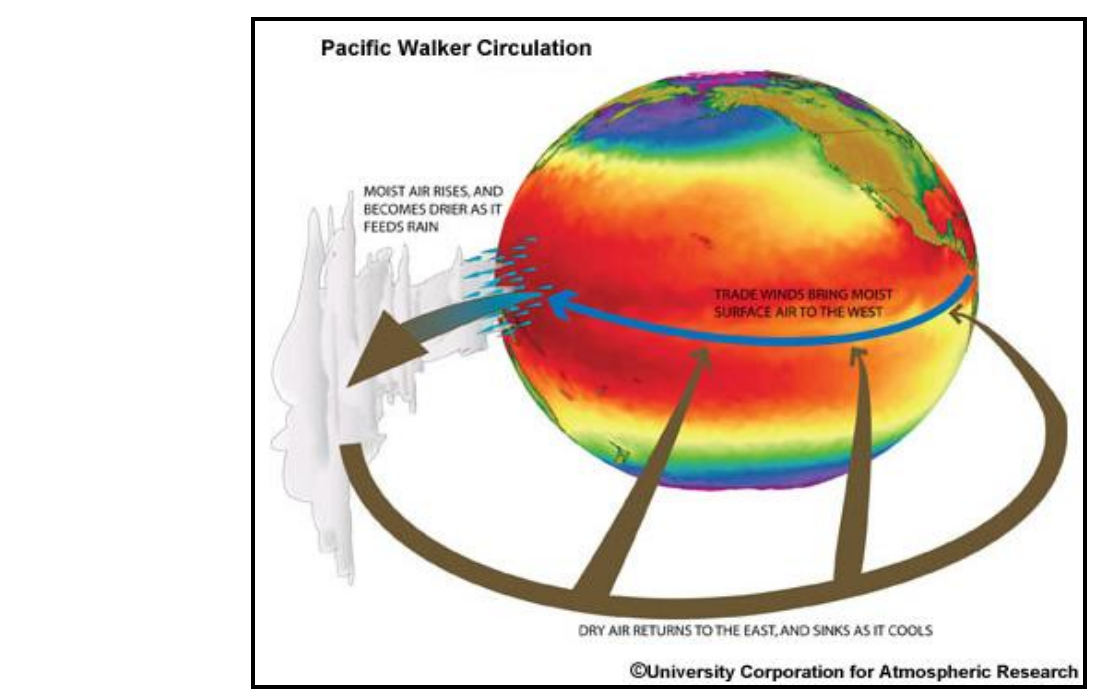

Figura 8 Esquema da Circulação de Walker sobre o Pacífico. Fonte: UCAR-McPhaden (2002)

Os fenômenos ENOS são caracterizados principalmente por alterações da TSM na bacia do Pacífico Equatorial e pelas modificações dos campos de pressão atmosférica e vento ao nível do mar, no Pacífico tropical. A oscilação das anomalias de pressão atmosférica entre os setores leste e oeste do Pacífico Sul dão origem ao nome Oscilação Sul. A ocorrência de eventos ENOS é normalmente dividida em duas fases distintas, quente (El Niño) e fria (La Niña), como destacam McPhaden (2002) e Trenberth (1997). O fenômeno ENSO apresenta uma periodicidade irregular, que varia entre dois e sete anos; apresenta anomalias de TSM em uma grande área (todo o Pacífico tropical), e seu impacto é global (Hanley, 2003). A componente oceânica na fase positiva do ENOS, o El Niño, é caracterizada pelo enfraquecimento dos ventos alísios e pelo aumento da TSM no Pacífico Equatorial centroleste (Figura 9). O fenômeno tem sido considerado como parte de um evento climático em escala global. Eventos de El Niño duram normalmente de 9 a 15 meses, segundo McPhaden (2002) e Larkin e Harrison (2002). O El Niño é caracterizado por anomalias de vento de oeste na região equatorial do Pacífico. Anomalias de oeste formam-se quando os ventos alísios se enfraquecem ou ainda quando ventos de oeste se desenvolvem devido a situações de fenômenos de grande escala. A Figura 9 evidencia como as águas superficiais do Pacífico Equatorial se modificam durante as várias fases do ENOS.

Para Wyrtk (1975; 1979), quando os ventos alísios se enfraquecem uma anomalia inicial de oeste no Pacífico central provoca a geração de uma onda de Kelvin que se propaga para leste e para baixo, no oceano. A propagação desta anomalia para baixo, no oceano, contribui 
para o processo de afundamento da termoclina no setor oeste do Pacífico e sua elevação na porção leste.

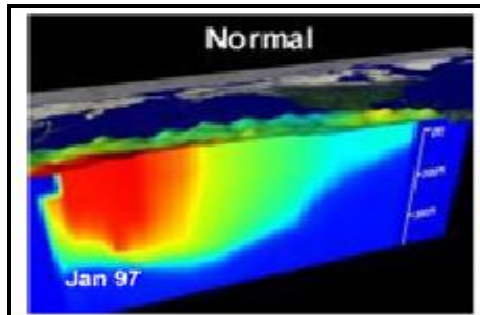

a)

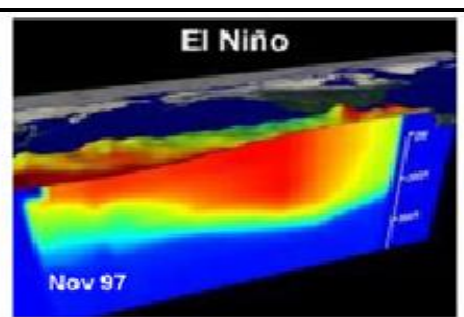

b)

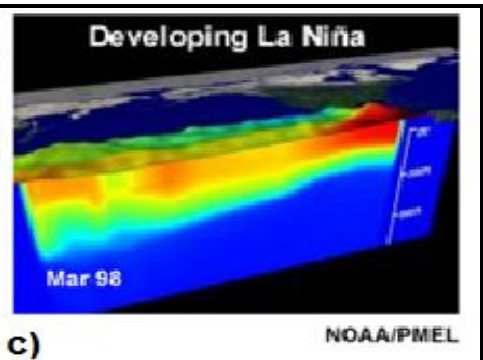

c)
NOAA/PMEL

Figura 9 Temperatura da superfície do mar e o perfil vertical da temperatura no Oceano Pacífico Equatorial ilustram como a lâmina superficial do oceano se altera durante a transição de (a) normal para (b) El Niño e, para (c) La Niña. Fonte: UCAR (2012)-NOAA-PMEL

As ondas de Kelvin ficam presas ao longo do setor equatorial (Figura 10) e têm centenas de quilômetros de extensão, velocidade de fase de 2-3 $\mathrm{m} \mathrm{s}^{-1}$, cruzando o Pacífico em aproximadamente três meses, como evidenciaram Roundy e Kiladis (2006). A Figura 10 ilustra a propagação de ondas de Kelvin e Rossby, para leste e oeste, respectivamente, no Oceano Pacífico, com base nos resultados obtidos por modelo idealizado.

A componente oceânica na fase negativa do ENSO, La Niña, está associada a ventos alísios mais fortes do que o normal e temperatura da superfície do mar mais baixas no Pacífico Equatorial centro-leste. Em média, as anomalias da TSM durante eventos de La Niña são menos extremas do que as de El Niño (Figura 9), mas tendem a durar mais, de um a três anos. As transições de El Niño para La Niña ocorrem muito mais rapidamente do que as de La Niña para El Niño; quase todas as transições de El Niño para La Niña ocorrem em um ano, como destacou Larkin e Harrison (2002). Embora existam muitas particularidades relacionadas aos eventos de ENOS a serem mais bem compreendidas, diversos foram os cientistas que postularam teorias sobre este assunto.

Em 1969, Bjerknes observou uma retro-alimentação positiva entre os ventos alísios e o gradiente zonal de TSM no Pacífico equatorial. Especificamente, postulou que a diferença de anomalias de TSM sobre o Pacífico Equatorial oeste, anormalmente quente, e Pacífico leste, anormalmente frio, levam a forte convecção na porção oeste. Esta convecção, por sua vez, determinaria fortes ventos alísios de leste que reforçariam o gradiente zonal de TSM por esfriar o Pacífico central e leste (fase La Niña). A condição oposta, um aquecimento anormal no Pacífico leste, levaria à formação de um evento de El Niño. Contudo, a teoria de Bjerknes 
não explica porque as condições anômalas de um evento ENOS poderiam terminar, quanto tempo o fenômeno poderia durar, ou, porque os eventos têm seu pico durante o inverno boreal (verão austral) (em fase com o ciclo sazonal). Assim como também não revela se o processo de retro-alimentação seria instável ou estável, na troca de energia entre a atmosfera e o oceano, e, nem revela se este processo poderia permanecer num mesmo estado por longos períodos, apesar da retro-alimentação presente.

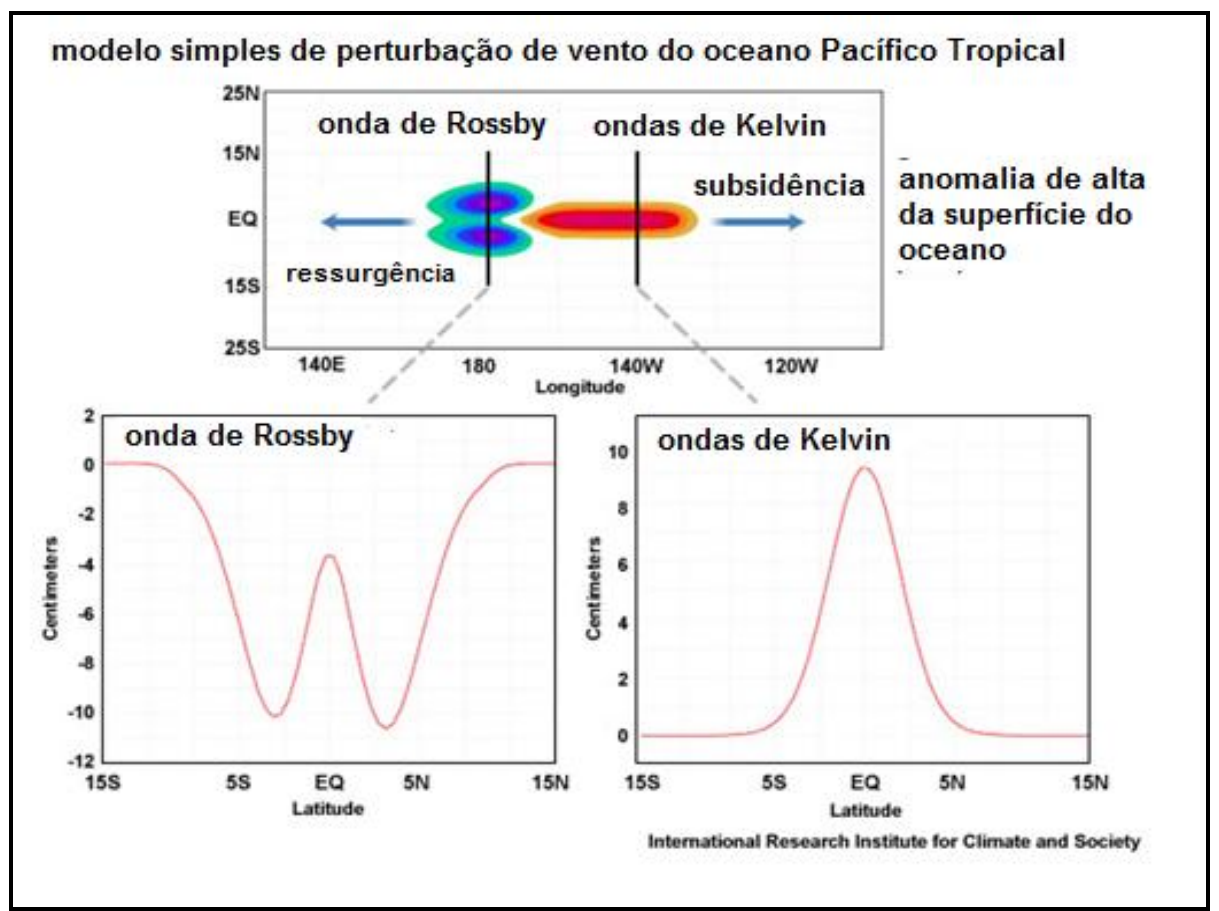

Figura 10 Modelo idealizado de uma onda de Kelvin equatorial movendo-se para leste pelo estresse do vento (vermelho e laranja), comparada com as ondas de Rossby, que se propagam para oeste. Fonte: UCAR (2012)-IRI

Além da teoria postulada por Bjerknes (1969), existe outra teoria formulada com base em observações da ocorrência de eventos ENOS, conhecida como Teoria do Oscilador Atrasado. Esta teoria é sustentada por análises dos processos dinâmicos associados ao acoplamento entre oceano e atmosfera, incluindo ainda o aquecimento atmosférico por convecção, a representação explícita da dinâmica da camada superficial e a dinâmica linear de água-rasa ao longo do equador. Esta teoria tem como prioridade evidenciar o crescimento de eventos de ENOS, levando em consideração todas as fases de existência do fenômeno, como indicado na Figura 11.

É de conhecimento da dinâmica da atmosfera que quando os ventos alísios enfraquecem, as anomalias de oeste persistem por vários meses e as ondas de Kelvin movem-se para leste, pelo equador (Wyrtk, 1975; 1979). 


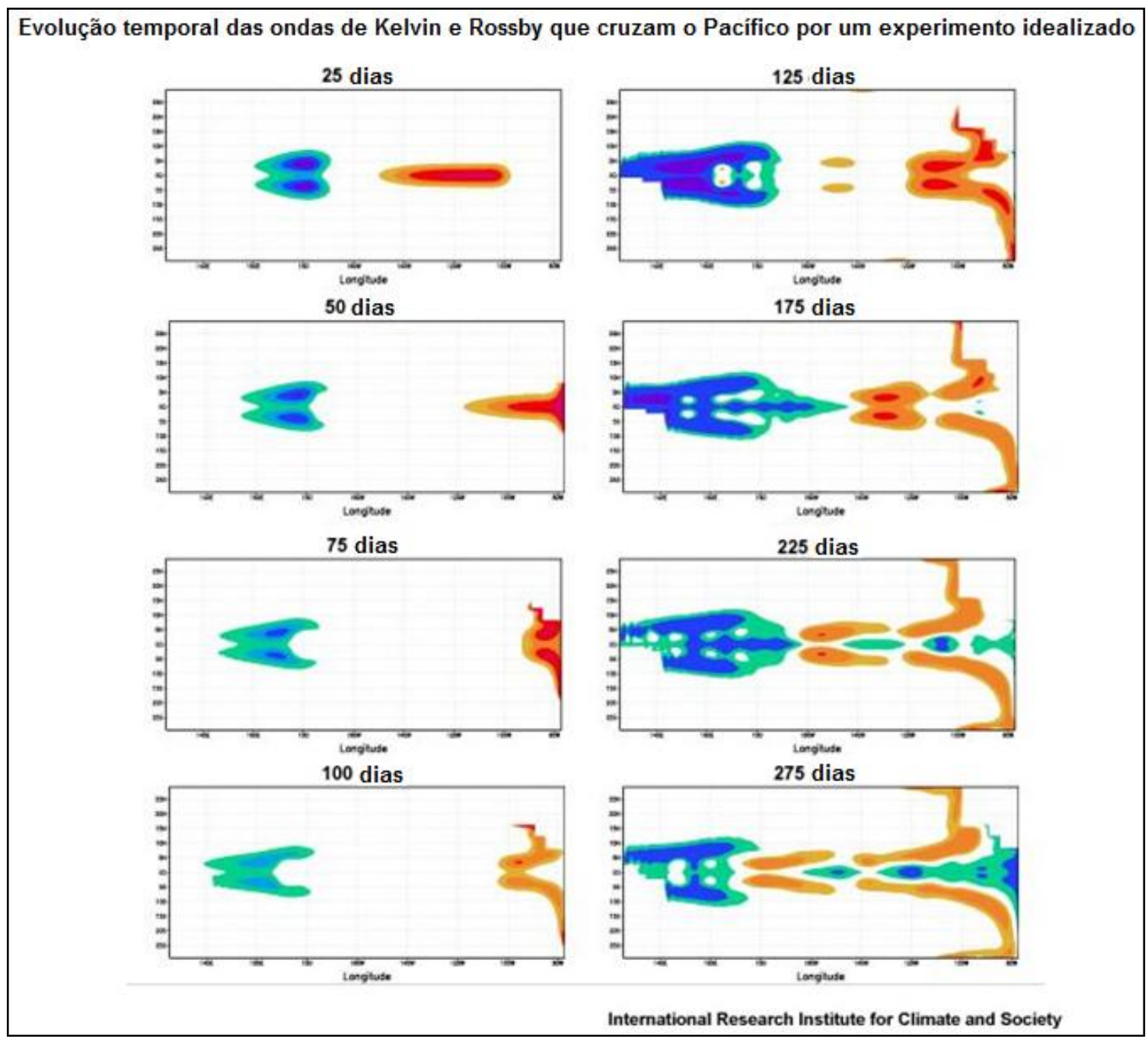

Figura 11 Evolução temporal da propagação de ondas para experimento linearizado. Fonte: UCAR (2012)-IRI

Coincidentemente com o movimento para leste das ondas de Kelvin há a propagação para oeste das ondas de Rossby, como já indicado na Figura 10. Nas águas do Pacífico adjacentes à costa oeste da América do Sul, a propagação para leste das ondas de Kelvin está associada à propagação de ondas de Rossby ressurgentes, que se espalham ao longo da costa e se movem para oeste, nos dois lados do equador (Figura 11 - dias 75-100). As ondas de Rossby que se propagam para oeste, numa faixa latitudinal de até 10 graus a partir do equador, são os modos de ondas de Rossby mais rápidos e geram uma termoclina mais rasa no oeste. Todos os modos mais lentos das ondas de Rossby são refletidos da fronteira oeste e se propagam para leste como ondas de Kelvin ressurgentes que aumentam a profundidade da termoclina no setor leste do oceano (Figura 11 - dias 125-175). Uma onda de Rossby leva aproximadamente oito meses para cruzar o Pacífico. A teoria do oscilador atrasado pode 
explicar a tendência de anomalias frias seguirem anomalias quentes e a escala de tempo típica de um evento El Niño. Entretanto, não explica o término de eventos frios.

Além da teoria do oscilador atrasado, outra teoria de funcionamento do ENOS que se destaca é a da recarga/descarga, segundo Jin (1997). Esta teoria é estruturada a partir dos preceitos de que o calor é acumulado na região equatorial oeste (Figura 12.I); é, então, descartado para leste e para o pólo durante os eventos de El Niño. O transporte de energia abaixo da camada de Ekman, no oceano, é a chave para a recarga e descarga postulada por esta teoria. A Figura 12 ilustra o processo.

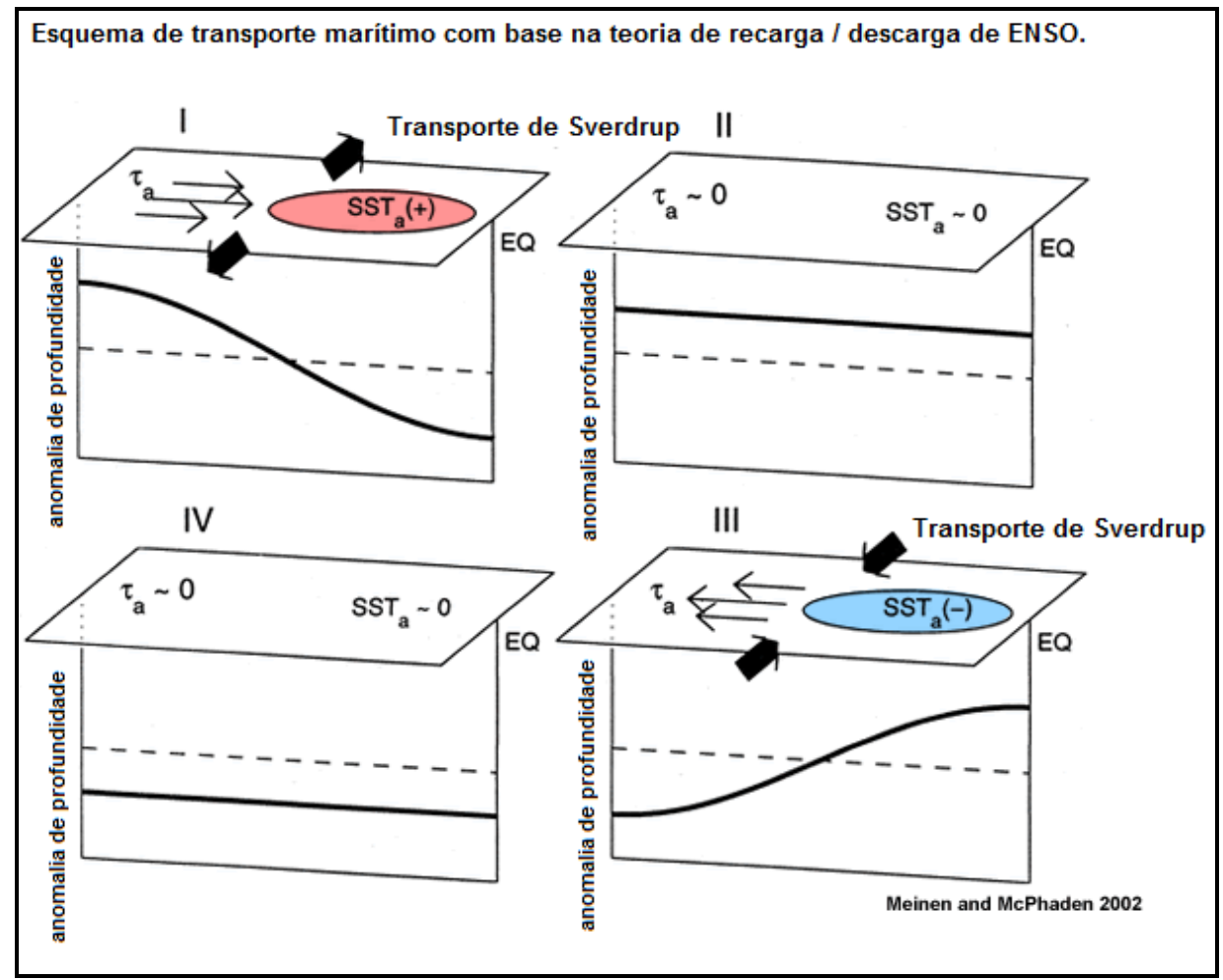

Figura 12 Esquema de transporte de energia no oceano com base na teoria de recarga/descarga, do ENSO. Fonte: Meinen e McPhaden (2002)

A primeira contribuição científica a observar que as diferentes fases do ENOS modificavam os campos de pressão da atmosfera na região do Pacífico tropical (Oscilação Sul) e o padrão de circulação atmosférica global foi feita por Walker, em 1924, posteriormente, mais bem compreendida por Troup (1965) e Bjerknes (1969). O Indice de Oscilação Sul, IOS, caracteriza a intensidade desta oscilação através do cálculo da diferença entre os desvios normalizados de pressão atmosférica em Taiti, na Polinésia Francesa, e em Darwin, norte da Austrália. A seguinte expressão matemática indica o cálculo:

$$
\text { IOS }=\Delta p_{T}-\Delta p_{D},
$$


em que $\Delta p_{T}$ e $\Delta p_{D}$ representam, respectivamente, o desvio normalizado da pressão atmosférica em Taiti e Darwin. O padrão espacial de anomalias de pressão atmosférica durante eventos de El Niño, observados por Walker durante as décadas de 1920 e 1930, está sintetizado na Figura 13, como descrito por McPhaden (2002).

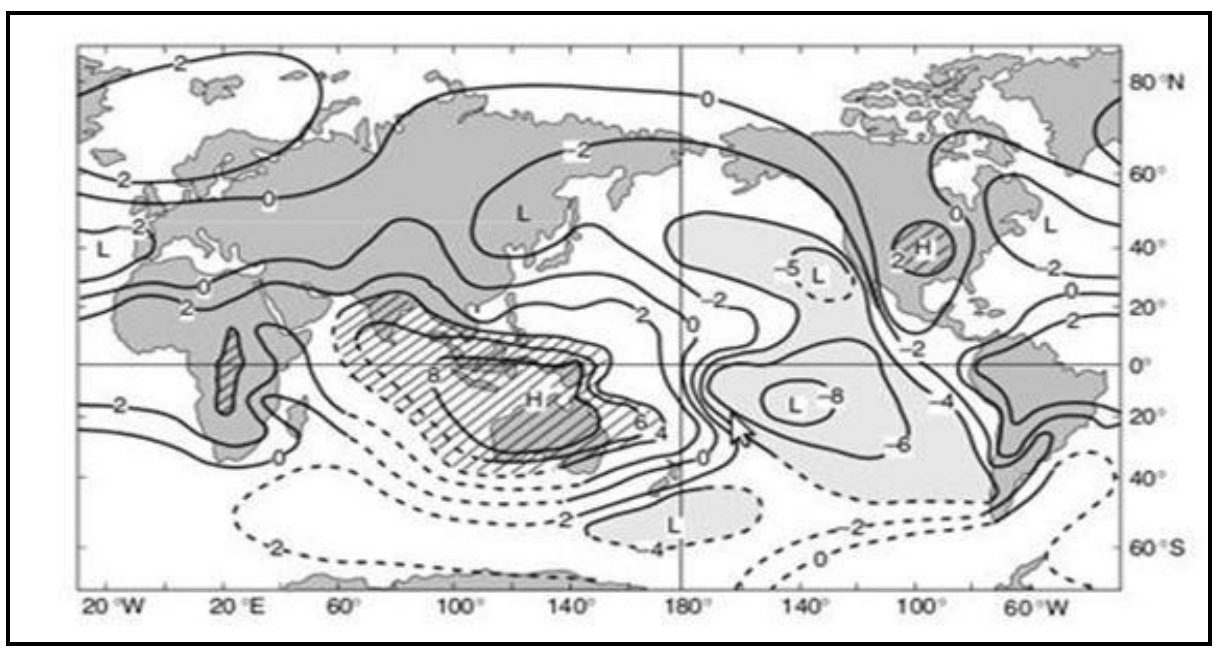

Figura 13 Padrão espacial da média anual de anomalias de pressão ao nível do mar (PNM) associadas à ocorrência de eventos negativos (Niño). Áreas hachuradas indicam onde a PNM varia em fase com Darwin, norte da Austrália, e áreas em cinza indicam onde a PNM varia fora de fase com Darwin. Fonte: McPhaden (1997).

O IOS está associado à intensidade e sentido dos ventos alísios na região equatorial do Pacífico (Walker, 1924). Quando esse índice é negativo (anomalias negativas de pressão em Taiti e, positivas em Darwin), os ventos alísios são mais fracos que o usual, ou, em situações intensas, podem até mudar de sentido, tornado-se de oeste. Quando o IOS é positivo, os ventos alísios são mais fortes do que o usual. As condições negativas do IOS são definidas por anomalias quentes de TSM, superiores a $0,5^{\circ} \mathrm{C}$ no Pacífico Equatorial (períodos de eventos EI Niño), enquanto que as condições positivas do IOS são determinadas por anomalias frias de TSM, inferiores a $-0,5^{\circ} \mathrm{C}$ (períodos de eventos Niña). A evolução temporal do IOS, entre 1900 e 2000, assim como anomalias de TSM no Pacífico Equatorial leste está indicada na Figura 14. Exemplos do acoplamento entre a anomalia de TSM e a fase do IOS podem ser observados durante o período de La Niña de 1973-76 e o de El Niño de 1983-84 (Figura 14). Estes períodos estão indicados na figura. Para o período de La Niña, as anomalias de TSM apresentam desvios negativos (Figura 14b), ao mesmo tempo em que são observados desvios positivos de IOS (Figura 14a). Durante o período de El Niño de 1982-83 nota-se o padrão inverso do descrito para o caso La Niña. 


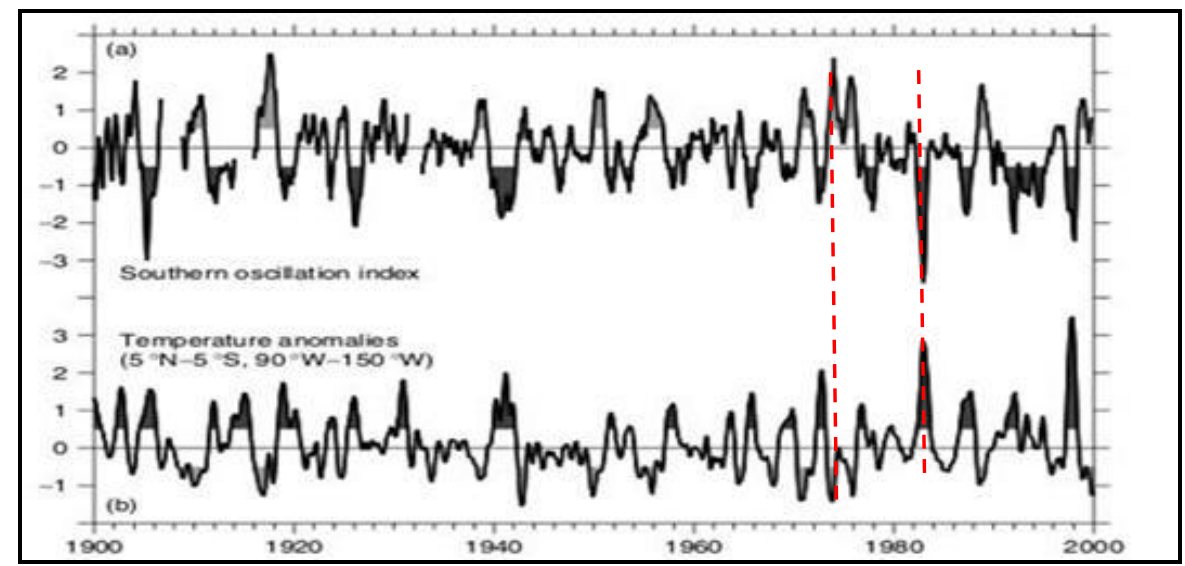

Figura 14 (a) IOS normalizado pela diferença da PNM entre Taiti e Darwin. Períodos de IOS com magnitude maior do que 0,5 estão sombreados para enfatizar a relação com episódios de El Niño e La Niña. O IOS negativo foi associado com aquecimento da superfície do mar (El Niño), e o positivo, com esfriamento da temperatura do mar (La Niña). (b) Anomalias de TSM (derivada da normal climatológica) para a região delimitada por 5N-5S e 90-150W, de 1900 a 1999. Anomalias positivas de TSM maiores do que $0,5^{\circ} \mathrm{C}$ são indicativos de eventos $\mathrm{El}$

Niño. Anomalias negativas inferiores a $-0,5^{\circ} \mathrm{C}$ indicam eventos La Niña. Fonte: McPhaden (2002)

A compreensão do funcionamento da Oscilação Sul e o entendimento de suas fases, além de ter contribuído enormemente à compreensão da variabilidade climática local, também favoreceram a condução de um grande conjunto de pesquisas que obtiveram resultados mais consistentes a respeito do comportamento de variáveis remotas, como a chuva (Ropelewski e Halpert, 1986; Aceituno, 1988; Andreoly e Kayano, 2007; Minuzzi et al., 2007), a temperatura do ar e a vazão de rios em regiões de várias partes do globo (Molion e Moraes, 1987; Mechoso e Iribarren, 1991; Aceituno, 1987; Ashouri 2010). Além da IOS, outros índices ganham destaques particulares em estudos de variabilidade climática, como é o caso da Oscilação Decadal do Pacífico (ODP, ou PDO, em inglês) e da Oscilação do Atlântico Norte (OAN, ou NAO, em inglês).

A Oscilação Decadal do Pacífico é um fenômeno de baixíssima frequência e foi descoberto por meio de observações vinculadas às atividades pesqueiras de salmão no Pacífico Norte, como destacado por Hare e Francis (1995) e Mantua et al. (1997), de forma semelhante às observações e descobertas de eventos de ENOS na faixa equatorial do Pacífico. Os trabalhos pioneiros produzidos sobre a PDO foram dedicados à reconstrução das séries temporais de dados e ao entendimento de suas fases. A partir dos padrões mensais de TSM e de anomalias de pressão atmosférica na bacia do Pacífico Norte, Trenberth (1990), Trenberth e Hurrell (1994), Latif e Barnett (1994 e 1996), Minobe (1997), Mantua et al. (1997), Zhang et al. (1997), Gershunov e Barnett (1998), Mantua e Hare (2002), dentre outros, elencaram as principais contribuições sobre esta oscilação. Aceita-se normalmente que a fase positiva da PDO ocorre quando as águas superficiais do interior da bacia do Pacífico Norte estão 
frequentemente mais frias que a média climatológica (anomalias negativas de TSM) mais quentes que o normal (anomalias positivas de TSM) ao longo da costa oeste e sul da América do Norte (Figura 16a), como destacado por Mantua el al. (1997). Combinadas a este padrão, as anomalias de pressão em superfície são mais baixas que o normal na costa da América do Norte do que no centro da bacia do Pacífico Norte. A fase negativa da PDO ocorre quando a configuração espacial das anomalias de TSM e a de pressão atmosférica são contrárias (Figura 15).

Esta oscilação é marcada ao longo de sua série histórica por dois longos ciclos. Suas fases positivas compreendem os intervalos entre 1925 e 1946 e entre 1977 e 1996 e suas fases negativas, entre 1900 e 1924 e entre 1947 e 1976. Após a década de 2000 a tendência é, aparentemente, de uma fase negativa da oscilação. Os intervalos decadais a multidecadais (Figura 15b) enaltecem a variabilidade de baixíssima frequência como a característica mais marcante desta oscilação, como mostram Minobe (1997) e Mantua et al. (1997).

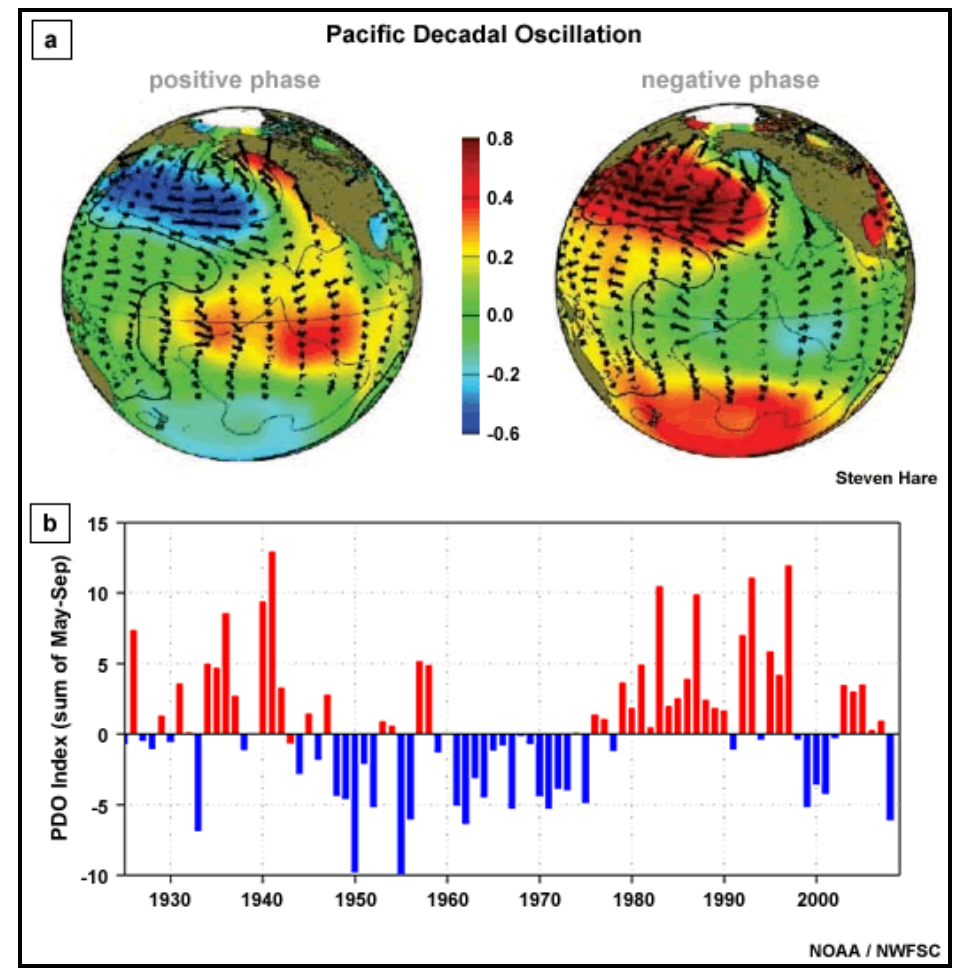

Figura 15 (a) Anomalias típicas de TSM (cores), pressão ao nível do mar (contornos), e estresse do vento em superfície (setas) durante as fases quente e fria da ODP. (b) Indice mensal de ODP, de 1925 a setembro de 2006. Fonte: UCAR (2012)-NOAA/NWFSC

O fato da PDO apresentar uma variabilidade de baixíssima frequência e alta energia possibilita modificações em outros fenômenos climáticos caracterizados por frequências maiores. Desta forma, a PDO pode modular os eventos de ENSO, como destacaram Zhang et 
al. (1997), Gershunov e Barnett (1998), Mann e Park (1996), Kumar e Hoerling (1997), Newman (2003) e Livezet et al. (1997). Com o uso de dados de TSM, pressão atmosférica e vento, Zhang et al. (1997) observaram que os padrões espaciais de PDO durante suas fases positivas e negativas, assemelhavam-se a alguns padrões de eventos ENOS (El Niño e La Niña), pontuando que estes últimos foram muito mais expressivos na faixa tropical e menos, nas latitudes mais altas. As três variáveis utilizadas neste estudo permitiram aos autores concluir que a variabilidade relacionada aos eventos de ENOS apresenta-se forçada por um ciclo interdecadal. Além disto, as médias durante os períodos de PDO e ENOS mostraram que as respostas da variabilidade da TSM, pressão e vento são menores na região tropical e maiores nos extratrópicos. Os padrões de pressão atmosférica descritos por Zhang et al. (1997) em períodos de PDO positiva e negativa assemelham-se aos padrões do Pacific North American (PNA).

A partir dos resultados obtidos por Zhang et al. (1997), Gershunov e Barnett (1998) sugeriram que a similaridade das respostas climáticas durante eventos de ENSO e PDO pode estar atrelada a uma lenta evolução da própria PDO que passaria a assumir um papel de moduladora de eventos ENOS. A forma esperada (e observada) desta modulação seria uma resposta climática mais forte (fraca) para períodos de El Niño (La Niña) durante as fases positiva (negativa) da PDO. De fato, todas as hipóteses levantadas por Gershunov e Barnett (1998) sobre a relação PDO-ENOS foram comprovadas pelos resultados do estudo.

Outra variabilidade de baixíssima frequência a ser destacada nesta revisão é a Oscilação do Atlântico Norte (NAO). Esta oscilação se configura como o padrão mais importante de variabilidade atmosférica do Atlântico Norte, desempenhando papéis importantes na configuração climática da costa leste da América do Norte e do setor oeste da Eurásia, como destacaram van Loon e Rogers (1978), Wallace e Gutzler (1981), Hurrell $(1995,1996)$ e Kushnir (1999). As primeiras observações da existência da NAO foram feitas por Walker (1924) e, posteriormente, mais bem descritas, em 1932, por Walker e Bliss. Neste último estudo, os autores definiram a NAO como a diferença de anomalias de pressão ao nível do mar entre as estações de medição da Islândia e dos Açores. Estudos posteriores verificaram que esta oscilação era marcada por uma fase positiva e outra negativa, como destacou Kushnir (1999). A fase positiva da NAO ocorre quando há anomalias mais intensas de pressão baixa (anomalias negativas de pressão) sobre a região da Islândia e, de pressão alta (anomalias positivas) sobre os Açores, durante o inverno do hemisfério boreal, tal como 
mostrado na Figura 15. Esta fase positiva é caracterizada por uma forte baixa subpolar ao norte (com movimento anti-horário) e uma forte alta subtropical mais ao sul (com movimento horário), padrão que acaba intensificando o escoamento de oeste sobre o Atlântico Norte. Quando isso ocorre, o transporte de ar quente e úmido proveniente da região do Golfo favorece o desenvolvimento de tempestades no Atlântico Norte.

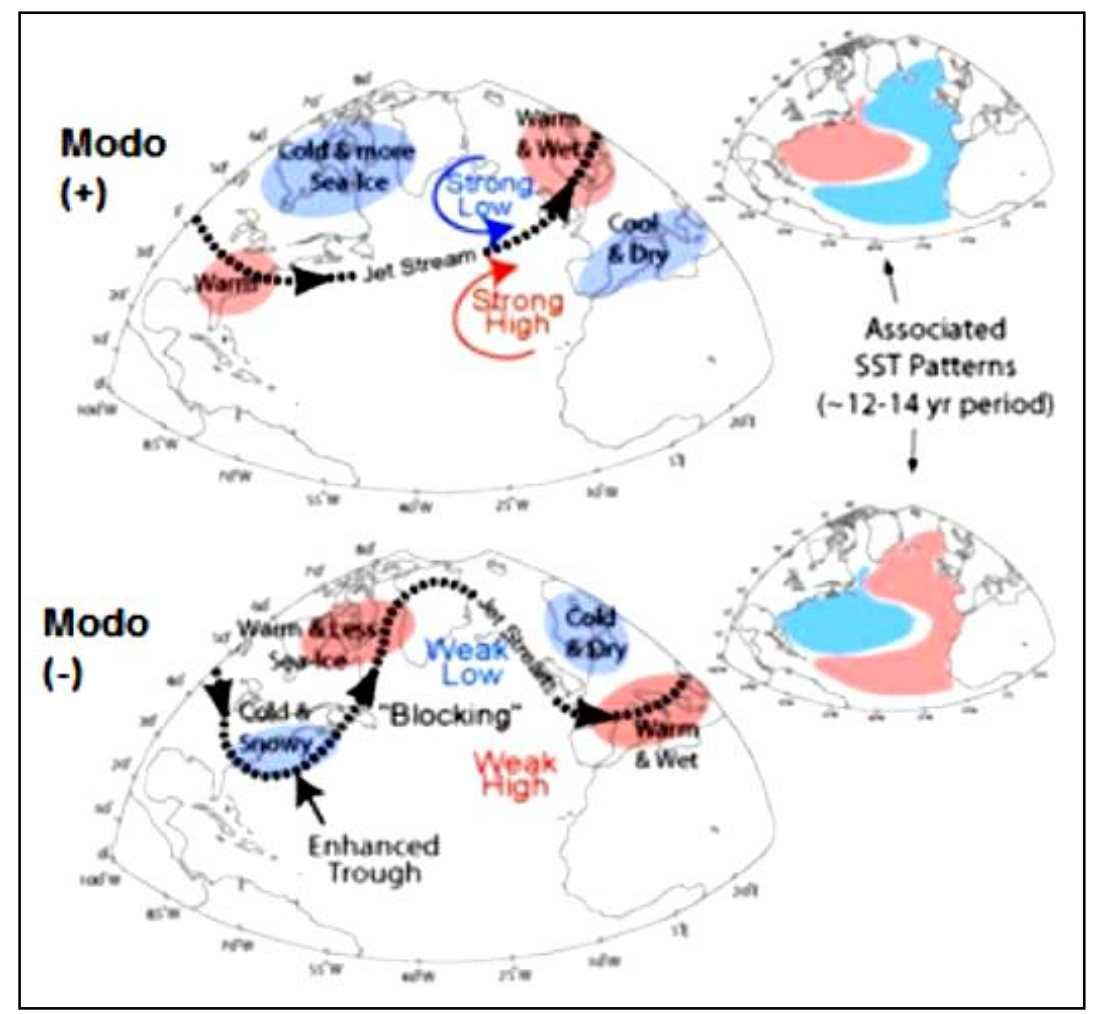

Figura 16 Fases da Oscilação do Atlântico Norte. (a) A representação na porção superior da figura mostra a fase positiva da NAO. Esta é marcada por intensificações da baixa subpolar e do anticiclone dos Açores. Quando isso ocorre temos o transporte de umidade e calor latente do Atlântico Norte - aquecido e úmido pela corrente do golfo - para as porções mais ao norte da Europa. Ao mesmo tempo, com a intensificação da baixa subpolar, fortes ventos sopram em direção à porção mais ao sul da Europa. (b) Durante a fase negativa da NAO, tem-se um padrão inverso das anomalias na região da Islândia e Açores. Nesta fase da oscilação ocorre a formação de grandes cavados e cristas responsáveis pelo transporte de calor para o sul da Europa. Fonte: NOAA (2012)

A fase negativa desta oscilação ocorre quando a baixa da Islândia e a alta subtropical dos Açores se enfraquecem. Nesta situação, o posicionamento das correntes de jato se difere do posicionamento que ocorre durante a fase positiva. Este aspecto propicia a reorganização das trajetórias de tempestades, segundo Rogers (1990), o que gera mudanças drásticas dos padrões regionais de temperaturas na Europa e, a nordeste do Canadá e dos Estados Unidos, segundo Kushnir (1999). Durante a fase negativa desta oscilação ocorre a formação de uma crista sobre a Groenlândia que permite o transporte de ar mais quente vindo das regiões de latitudes mais baixas o que garante o surgimento de anomalias positivas de temperatura 
sobre a região. A leste desta crista ocorre a formação de um sistema de cavado (sobre a Islândia) que reforça a entrada de ar frio vindo das regiões das latitudes mais altas, permitindo a formação de anomalias negativas de temperatura em áreas continentais de latitudes mais baixas da Europa, tal como discutiram Jones e Davis (1995) e Hartley e Keebles (1998) (Figura 16). Além disto, com o cavado deslocado para dentro da bacia do Atlântico Norte, tempestades são desenvolvidas, como destacou Colucci (1976), e intensificadas com a presença de anomalias positivas de TSM vindas da região do Golfo, como destacou Hartley (1996). O enfraquecimento do giro horário da alta subtropical dos Açores, observado durante a fase da negativa da NAO, modifica os ventos alísios de nordeste, deixando-os menos intensos, e causando a redução do transporte de umidade para o setor centro-norte da América do Sul (Silva, 2010).

A compreensão dos processos envolvidos na Oscilação do Atlântico norte torna-se mais complexa ao se considerar o seu posicionamento. A região da Islândia está muito próxima de uma das áreas (mar da Noruega) onde ocorre o afundamento das águas oceânicas provindas da circulação geral dos oceanos, circulação termohalina, como destacou Broecker (1991). É no mar da Noruega onde as águas superficiais afundam e onde são renovadas suas condições térmicas, como destacaram Stommel e Arons (1960). A intensidade deste afundamento é de aproximadamente $20 \mathrm{~Sv}$ (Swerdrup), o que é igual a 1 milhão de $\mathrm{m}^{3} \mathrm{~s}^{-1}$ de água que saem das áreas mais superficiais e se direcionam para as profundezas dos oceanos. Segundo Hall e Bryden (1982), o afundamento das águas no mar da Noruega libera aproximadamente 1,2 \pm 0,3 PW (1 PW = 10 ${ }^{15}$ Watts) de energia. Esta liberação de calor para a atmosfera desempenha certamente um papel importante na moderação do clima e nos estados de tempo do norte da Europa.

Por fim, o último índice a ser destacado nesta revisão específica, e que desempenha papel relevante na variabilidade climática da América do Sul, é o Modo Anular Sul ou South Annular Mode, SAM. O Modo Anular Sul é caracterizado pela diferença meridional de anomalias de pressão atmosférica ao nível médio do mar entre $40^{\circ} \mathrm{S}$ e $65^{\circ} \mathrm{S}$, segundo Rogers e van Loon (1981) e Gong e Wang (1998). As primeiras considerações científicas que notificaram a existência de uma oscilação nas altas latitudes do hemisfério sul foram realizadas por Walker (1928). Estas evidências foram postuladas no referido trabalho da seguinte forma: 
cinturão de alta pressão entre o Chile/Argentina e a área de baixa pressão no mar de Weddell e de Bellingshausen, na Antártica." (tradução livre)

Décadas mais tarde e com o uso de um conjunto maior de dados de pressão atmosférica para o hemisfério sul, Kidson (1975), Rogers e van Loon, (1981), Mo e White, (1985), Mo (1986), Connolley (1997) e Gong e Wang (1998) comprovaram as primeiras observações de Walker, em 1928. Kidson (1974), ao utilizar dados médios de pressão, temperatura e chuva para 1900 estações em torno do globo, para o segmento temporal de 1951 a 1960, observou a presença de um padrão de anomalias com variação meridional entre as regiões de latitudes extratropicais e subtropicais do hemisfério sul. Aproveitando os resultados obtidos por Kidson (1974), Rogers e van Loon (1982) mostraram que as anomalias médias de pressão e altura geopotencial em $500 \mathrm{hPa}$ sobre a Antártica apresentavam sinais contrários quando comparadas às observadas nas latitudes próximas à porção sul do Chile/Argentina. Esse fato contribui para o fortalecimento e enfraquecimento do vento zonal, sugerindo a existência de fases nesta oscilação.

A fase positiva do SAM ocorre quando há predomínio de anomalias negativas de TSM na região da Antártica e, positivas na região de latitudes médias. Durante esta fase, os ciclones extratropicais e frentes frias acabam se deslocando mais para as regiões próximas à Antártica. Nas latitudes médias, as regiões do cinturão de alta pressão do hemisfério sul acaba modificando o deslocamento e a intensidade dos sistemas transientes durante a fase positiva do SAM, como observado por Carvalho et al. (2005) e Reboita et al. (2009). A fase negativa desta oscilação ocorre quando há o predomínio de anomalias positivas de geopotencial sobre a Antártica e, negativa ao redor da região de latitudes médias. Nesta fase, a frequência de ciclones extratropicais e frentes frias sobre as latitudes médias é maior (Carvalho et al., 2005; Reboita et al., 2009). Reboita et al. (2009) observaram que durante a fase negativa do SAM, os jatos subtropicais ficam enfraquecidos, favorecendo a propagação de sistemas transientes na região. Nesta fase, foram observadas anomalias positivas de chuva para o sudeste do Brasil, Uruguai e centro da Argentina durante as estações de verão e outono, para o período de 1980 a 1999. Na fase positiva da Oscilação Antártica, o movimento ondulatório subtropical apresenta deslocamento para a porção mais ao sul, o que está associado à menor quantidade de ciclones que cruzam a América do Sul, como destacou Carvalho et al. (2005). Durante a fase positiva da Oscilação Antártica, os jatos 
subtropicais ficam fortalecidos, propiciando menores anomalias de precipitação no interior na América do Sul, particularmente no outono.

\section{CONSIDERAÇÕES FINAIS}

Os resultados obtidos por estudos explicativos dos mecanismos físicos e dinâmicos do sistema climático (oceano e atmosfera) são necessários à compreensão dos processos responsáveis pela ocorrência da variabilidade climática. Embora muitos processos climáticos tenham sido mais bem compreendidos no decorrer das últimas décadas, há ainda muito a se conhecer. A compreensão e conhecimento dos processos climáticos permitem, em última instância, melhorar a previsibilidade do clima.

No contexto dos debates atuais sobre o clima, que ocorrem devido à sua grande importância para a vida no planeta, temas como a variabilidade climática e o aquecimento do planeta constituem áreas de importante investigação científica. A demonstração de teorias e processos climáticos físicos e dinâmicos, evidenciando a complexidade a eles inerente, motivou a elaboração da presente revisão.

\section{REFERÊNCIAS}

AMBRIZZI, T. (2003). El Niño/La Niña; Teleconexão Atmosférica. (Livre-docência). IAG/USP.

ACEITUNO, P. (1988). The Interannual Variability of South American Climate and the Southern Oscillation. Thesis (PH.D.) - The University of Wisconsin-Madison.

ACEITUNO, P. (1988). On the functioning of the southern oscillation in the South American sector. Part I: surface climate. Monthly Weather Review, 116, 505-524.

ACEITUNO, P. (1989). On the functioning of the southern oscillation in the South American sector. Part I: surface climate. Journal of Climate, vol. 2, issue 4. pp 341-355.

ANDREOLI, R.V. e KAYANO, M.T. (2007). A importância relativa do Atlântico Tropical Sul e Pacífico Leste na variabilidade de precipitação do Nordeste do Brasil. Revista Brasileira de Meteorologia. V. 22, n.1, 63-74. 
ASHOURI, H., ABRISHAMCHI, A., MORADKHANI, H. e TAJRISHY, M. (2010). Assessment of Interannual and Interdecadal Climate Variability Effects on Water Supply in Zayandeh-rood River Basin, Iran.

BARBANO, M.T.; SAWAZAKI, E.; BRUNINI, O.; GALLO, P.B.; PAULO, E.M. (2001). Temperaturabase e acumulo térmico no subperíodo emergência-florescimento masculino em cultivares de milho no Estado de São Paulo. Revista Brasileira de Agrometeorologia, Santa Maria, v.9, n.2, p. 261-268.

BATTISTI, D. S e HIRST, A.C. (1989). Interannual variability in a tropical atmosphere ocean model - influence of the basic state, ocean geometry and nonlinearity. J. Atmos. Sci., 46, 1687-1712.

BERBERY, H. e NÚÑEZ, M.N. (1989). An Observational and numerical study of blocking episodes near South America. Journal of Climate, 2, 1351-1361.

BERGERON, T. (1939). Richtlinieneiner dynamischen klimatologie. Met.Z.Braunschweig: 47:246-62.

BEROUTCHACHVILI, N. e MATHIEU, J.L. (1977). L'Etologie des géosystemes. L'Espace Géographique, t. 6, n.2, 1977, pp. 73-84.

BEROUTCHACHVILI e PANAREDA, J.M. (1977). Tendencia actual de la ciencia del paisaje em la Unión Soviética: el estudio de los geosistemas en la estación de Martkopi (Georgia). Revista de Geografia, Barcelona. vol. 11, n. 1-2, pp. 23-36.

BERLATO, M.A; Farenzena, H; FONTANA, D.C. (2005). Associação entre El Niño oscilação Sul e a produtividade de milho no Estado do Rio Grande do Sul. Pesquisa Agropecuária Brasileira, v.40, p.423-432.

BERTRAND, G. (1972). Paisagem e Geografia Física global: um esboço metodológico. Caderno de Ciências da Terra. N.13. São Paulo. IGUSP. 27p.

BROECKER, W.S. (1991). The great ocean conveyor. Oceanography. 4. 79-89.

BJERKNES, V. (1921). On the dynamics of the circular vortex with application to the atmosphere and atmospheric vortex and wave motions. Geof. Publ. Oslo. 
BJERKNES, J. (1969). Atmospheric teleconnections from the Equatorial Pacific. Monthly Weather Review, vol. 97, number 3, March.

BOLÓS, M.I.C. (1981). Problemática actual de los estudios de paisaje integrado. Revista de Geografia. Barcelona. V.15. n1-2. p. 45-68.

BRIGATTI, N. (2008). Variação do nível do mar associada aos tipos de tempo na geração de episódios extremos no município de Ubatuba/SP. (Dissertação de Mestrado) FCT-UNESP de Presidente Prudente.

CARDOSO, A.O. e DIAS, P.L.S. (2002). Relação entre a vazão de alguns rios do Estado de São Paulo e anomalias de TSM no Atlântico e Pacífico. XII Congresso Brasileiro de Meteorologia, Foz de Iguaçu-PR. 1077-1086.

CARDOSO, A.O., DIAS, P.L.S. e CHAMRRO, L. (2004). O uso de TSM e vazão como preditores de vazão no Rio Paraná. CBMET - anais do congresso brasileiro de meteorologia - Fortaleza.

CARDOSO, A.O. (2005). Relações entre a TSM nos oceanos Atlântico e Pacífico e as condições climáticas nas Regiões Sul e Sudeste do Brasil. (tese de doutorado) IAG/USP.

CAVALCANTI, I.F.A e AMRBIZZI, T. (2009). Teleconexões e suas influências no Brasil. In: Iracema Fonseca de Albuquerque Cavalcanti; Nelson Jesus Ferreira; Maria Gertrudes Alvarez Justi da Silva; Maria Assunção Faus da Silva Dias. (Org.). Tempo e Clima no Brasil. São Paulo: Oficina de Textos, 2009, p. 317-335.

CHARNEY, J. G. (1963). A note on large scale motions in the tropics. J. Atmos. Sci., 20, 607609.

CHARNEY, J. G. (1969). A further note on large scale motions in the tropics. J. Atmos. Sci., 26, 182-185.

COELHO, C.A. (2001). Anomalias de precipitação sobre a América do Sul e sua relação com a temperatura da superfície do mar dos oceanos Pacífico e Atlântico durante períodos de extremos da Oscilação Sul. Dissertação IAG/USP. 
COLUCCI, S.J. (1976). Winter Cyclone Frequencies over the eastern United States and adjacent western Atlantic, 1964-1973. Bulletin of the American Meteorological Society, 57(5), 548-553.

CONTI, J.B. (1975). Circulação secundária e efeito orográfico na gênese das chuvas na região lesnordeste paulista. São Paulo. (Série teses e monografias) USP/IG.

CONNOLLEY, W. M. (1997). Variability in annual mean circulation in southern high latitudes, Climate Dynamics, 13,745-756.

FREDERIKSEN, J.S. e WEBSTER, P. (1988). Alternative theories of atmospheric teleconnections and low frequency fluctuations. Rev.Geophys., 26:459-494.

GOMES FILHO, M.; SOUSA, F de A.S e CAVALCANTI, E.P. (2000). Relação entre as vazões médias mensais do Rio Piancó e as anomalias de Temperatura da Superfície dos Oceanos Atlântico e Pacifico Tropical. Revista Brasileira de Engenharia Agrícola e Ambiental. V.4, n.2, p304-308.

GONG, D.Y., e WANG, S.W. (1998) Antarctic oscillation: concept and applications. Chinese Sci. Bull., 43,734-738, 1998.

HANLEY, D. E.; BOURASSA, M. A.; O'BRIEN, J. J.; SMITH, S. R. e SPADE, E. R. (2003). A quantitative evaluation of ENSO indices. J. Climate, 16, 1249-1258.

HANN, J. von (1903). Handbook of climatology. The MacMillan company, 1903. 437 páginas.

HARE, S.R. e FRANCIS, R.C. (1995). Climate change and salmon production in the Northeast Pacific Ocean. Can. Spec. Publ. Fish. Aquat. Sci. 121, 357-372.

HARTLEY, S e KEEBLES, M.J. (1998). Synoptic Associations of winter Climate and Snowfall Variability in New England. International Journal of Climatology 18: 281-298.

HOREL, J. D.L e WALLACE, J.M. (1981). Planetary scale atmospheric phenomena associated with the Southern Oscillation. Mon. Wea. Rev., 109: 813-829.

HOSKINS, B.J. e KAROLY, D.L. (1981).The steady linear response of a spherical atmosphere to thermal and orographic forcing. J. Atm. Sci., 38: 1179-1196. 
HURRELL, J.W. (1995). Decadal trends in the North Atlantic Oscillation: Regional temperatures and precipitation. Science 269:676-679.

HURRELL, J.W. (1996) Influence of variations in extratropical wintertime teleconnections on Northern Hemisphere temperature. Geophys Res Lett 23:665-668.

JIN, F. (1997). An equatorial ocean recharge paradigm for ENSO. Part I: Conceptual model. J. Atmos. Sci., 54, 811-829.

JONES, G.V. e DAVIS, R.E. (1995). Climatology of Northeasters and the $30 \mathrm{kPa}$ Jet. Journal of Coastal Research (11), p. 1210-1220.

KAROLY, D.J. (1989). Southern Hemisphere circulation features associated with El NiñoSouthern Oscillation events. Journal Climate. 2, 1239-1252.

KIDSON, J. W. (1975). Eigenvector analysis of monthly mean surface data, Mon. Wea. Rev, $103,177-186$.

KUMAR, A., e HOERLING, M.P. (1997). Interpretation and implications of the observed interEl Niño variability. J. Climate, 10, 83-91.

KUSHNIR, Y. (1999). Europe's winter prospects. Nature 398:289-291.

LARKIN, N.K. e HARRISON, D.E. (2002). ENSO warm (EI Niño) and cold (La Niña) event life cycles: Ocean surface anomaly patterns, their symmetries, asymmetries, and implications. J. Climate, 15, 1118-1140.

LATIF, M., e BARNETT, T.P. (1994). Causes of decadal climate variability over the North Pacific and North America. Science, 266, 634-637.

LATIF, M., e BARNETT, T.P. (1996). Decadal climate variability over the North Pacific and North America: Dynamics and predictability. J. Climate, 9, 2407-2423.

LAU, N e PHILLIPS, T.J. (1986). Coherent fluctuations of extratropical geopotential height and tropical convection in interseasonal time scales. J. Atmos. Sci., 43, 1164-1181. 
LI, B. e CLARKE, A. J. (1994). An examination of some ENSO mechanisms using interannual sea level at the eastern and western equatorial boundaries and the zonally averaged equatorial wind. J. Phys. Oceanogr., 24, 681-690.

LIVEREZ, R. E., MASUTANI, M., LEETMA, A., RUI, H., JI, M., e KUMAR, A., (1997). Teleconnective response of the Pacific-North American region atmosphere to large central equatorial Pacific SST anomalies. J. Climate, 10, 1787-1820.

LORENZ, E. (1963). The mechanics of vacillation. J. Atmos. Sci., 20, 448-464.

KAROLY, D.J. (1989). Southern Hemisphere circulation features associated with El NiñoSouthern Oscillation events. Journal Climate, 2, 1239-1252.

MANN, M.E e PARK, J. (1996). Join spatiotemporal modes of surface temperature and sea level pressure variability in the Northern hemisphere during the last century. Journal Climate. 9. 2137-2139.

MANTUA, N. J., S. R. HARE, Y. ZHANG, J. M. WALLACE, AND R. C. FRANCIS. (1997). A Pacific interdecadal climate oscillation with impacts on salmon production. Bull. Amer. Meteor. Soc., 1069-1079.

MANTUA, N.J. e HARE, S.R. (2002). The Pacific Decadal Oscillation. Journal of Oceanography, Vol. 58, pp. 35-44.

MANTUA, N. J. e BATTISTI, D. S. (1994). Evidence for the delayed oscillator mechanism for ENSO: the "observed" oceanic Kelvin mode in the far western Pacific. J. Phys. Oceanogr., 24, 691-699.

MCPHADEN, M.J. (2002). El Niño and La Niña: causes and global consequences. Encyclopedia of Global Environmental Change, Anonymous John Wiley and Sons, LTD, 353-370.

MECHOSO, C.R., IRIBARREN, G. P., (1991) Streamflow in southeastern South America and the Southern Oscillation. Journal of climate. (5) 1535-1539.MO, K.C. , and GHRIL, M. (1987):, Statistics and dynamics of persistent anomalies. J. Atmos. Sci., 44, 877-901.

MINOBE, S., (1997). A 50-70 year climatic oscillation over the North Pacific and North America. Geophys. Res. Lett., 24, 683-686. 
MINUZZI, R.B, SEDIYAMA, G.C, COSTA, J.M.N e VIANELLO, R.L.(2007) Influência da La Niña na estação chuvosa da região sudeste do Brasil. Revista Brasileira de Meteorologia. V 22, n.3, 345-353.

MO, K.C. e GHIL, M. (1987). Statistics and dynamics of persistent anomalies. Journal of the Atmosphere Sciences. 144, 808-823.

MO, K.C e NOGUÉS-PAEGLE, J. (2001). The Pacific-South American modes and their downstream effects. Int. J. Climatol., 21: 1211-1229.

MO, K.C. e HIGGINS, R.W. (1997). The Pacific-South American Modes and Tropical Convection during the Southern Hemisphere Winter. Mon. Wea. Rev., 126, 1581-1596.

MO, K. C., e WHITE, G.N. (1985). Teleconnections in the Southern Hemisphere. Mon.Wea. Rev. 113, 22-37, 1985.

MO, K. C., (1986). Quasi-stationary states in the Southern Hemisphere. Mon.Wea.Rev., $114,808-823$.

MOLION, L.C.B e MORAES, J.C., (1987). Oscilação Sul e descargas de rios na América do Sul Tropical. Revista Brasileira de Engenharia. Caderno de Recurso Hídrico. 5, 53-63.

MONTEIRO, C.A.F. (1976). O clima e a organização do espaço no estado de São Paulo: problemas e perspectivas. São Paulo: IGEOG.

MONTEIRO, C.A.F. (1971). Análise Rítmica em Climatologia. Climatologia 1, São Paulo. IGEOG/USP, 1971.

MONTEIRO, C.A.F. (2000). Geossistemas: a história de uma procura. São Paulo: Contexto/GeoUSP. (Novas abordagens 3). 127p.

MÜLLER, G.V. e AMBRIZZI, T. (2007). Teleconnection Patterns and Rossby Wave Propagation Associated to Generalized Frosts over Southern South America. Clim.Dyn., 29, No. 6, 633645.

MURAKAMI, T e UNNINAYAR, M.S. (1977). Atmospheric circulation during December 1970 through February 1971. Mon.Wea.Rev., 105, 1024-1038. 
NAMIAS, J. (1951). General aspects of extended range forecasting, Compendium of meteorology, Amer. Meteor.Soc., 802-813.

NEWMAN, M., COMPO, G.P. e ALEXANDER , M.A., (2003). ENSO-Forced Variability of the Pacific Decadal Oscillation . Journal of Climate., 16, n. 23., 3858-3857.

PHILANDER, S.G.H. (1990). El Niño, La Niña and the Southern Oscillation. Academic Press, New York 289 pp.

REBOITA, M.S, AMBRIZZI, T. e ROCHA, R.P. (2009). Relationship between the Southern Annular Mode and Southern Hemisphere Atmospheric Systems. Revista Brasileira de Meteorologia, v.24, n.1, 48-55.

REX, D.F. (1950). Bloking action in the middle troposphere and its effects upon regional climate. Part I: An aerological study of blocking action. Tellus, 2, 196-211.

RIVAS-KAINAY, E. e MERKINE, L.O. (1981). A simple mechanism for blocking. Journal of the Atmospheric Science. 38. 2077-2091.

ROSSBY, C.G. (1938.). Fluid mechanics applied to the study of atmospheric circulation. A study of flow patterns with the aid of isentropic analysis. Chicago. Man Inst. Technolg.125 pp.

ROGERS, J. R., e VAN LOON, H. (1981). Spatial variability of sea level pressure and $500 \mathrm{mb}$ height anomalies over the Southern Hemisphere, Mon Wea Rev,110,1375-1392.

ROGERS, J.C., (1990). Patterns of Low-Frequency Monthly Sea Level Pressure Variability (1899-1986) and Associated Wave Cyclone Frequencies. Journal of Climate, vol. 3, pp. 13641379

ROPELEWSKI, C.F e HALPERT, M.S. (1986). North Atlantic precipitation and temperature patterns associated with the El Niño/Southern Oscillation (ENSO). Monthly Weather Review. Volume 114, pp. $2352-2362$.

ROUNDY, P.E. e KILADIS, G.N. (2006). Observed relationships between oceanic Kelvin waves and atmospheric forcing. J. Climate, 19, 5253-5272. 
SANT'ANNA NETO, J.L. (1990). Ritmo climático e a gênese das chuvas na Zona Costeira Paulista. (Dissertação de Mestrado). FFLCH/USP.

SEIKI, A. e TAKAYABU, Y. N. (2007). Westerly wind bursts and their relationship with intraseasonal variations and ENSO. Part II: Energetics over the western and central Pacific. Mon. Wea. Rev.,135, 3346-3361.

SILVA, Carlos Batista. (2012). Variabilidade climática nos oceanos e a vazão fluvial no Pantanal brasileiro. (Dissertação de Mestrado). FFLCH/USP. pág. 202.

SILVA, G.A.M. (2010). (notas de aula) Introdução a variabilidade de baixa freqüência e teleconexões. IAG/USP. disponível em: http://www.dca.iag.usp.br/www/material/ ambrizzi/clima1/clim1_variabilidade_de_baixa_frequencia.pdf. Acessado em <10/12/2011>.

SOCHAVA, V.B. (1977). O estudo de geossistemas. Métodos em questão, n.16, IGUSP. São Paulo. 51p.

STOMMEL, H e ARONS, A. B. (1960). On the abyssal circulation of the world ocean. I. Stationary planetary flow patterns on a sphere. Deep-Sea Res. 6., 140-154.

SZEREDI, I e KAROLY, D. (1987a). The vertical structure of monthly fluctuations of the Southern Hemisphere troposphere. Australian Meteorological Magazine., 35:19-30.

SZEREDI, I e KAROLY, D. (1987b). The horizontal structure of monthly fluctuations of the Southern Hemisphere troposphere from station data. Australian Meteorological Magazine 35: 119-129.

TARIFA, J.R. (1975). Os fluxos polares e a chuvas da primavera-verão no Estado de São Paulo: uma análise quantitativa do processo genético. (Série Teses e Monografias). IGEOG/USP. São Paulo.

TRENBERTH, K.E. (1986). The signature of a bloking episode on the general circulation in the Southern Hemisphere. Journal of the Atmospheric Science. 43. 2061-2069.

TREMBERTH, K.E. (1990). Recent observed interdecadal climate changes in the Northern Hemisphere. Bull. Amer. Meteor. Soc., 71,988-993, 1990. 
TREMBERTH, K.E. (1997). The definition of El Niño. Bull. Amer. Meteor. Soc., 78, 2771-2777.

TROUP, A.J. (1965). The southern oscillation. Q.J.R. Meteorol. Soc., 91.490-506.

VERBICKAS, S. (1998). Westerly wind bursts in the tropical Pacific. Weather, 53, 282-284.

ZHANG, Y., WALLACE, M., BATTISTI, D.S. (1997) ENSO-like interdecadal variability: 1900-93. Journal climate. 10., 1004-1020.

ZAVATINI, J.A. (1990). A Dinâmica Atmosférica e a Distribuição das Chuvas no Mato Grosso do Sul. (Tese de Doutorado) FFLCH/USP.

WALKER, G.T (1924). Correlation in seasonal of weather. Memoirs of the India Meteorological Department. V. XXIX. (1926).

WALKER, G.T. (1928). World weather, Q. J. R. M. S., 54, 79-87.

WALKER , G.T. e BLISS, E.M. (1932). World Weather. V Mem. Roy. Meteor. Soc., 4:53-84.

WEBSTER, P.J. e HOLTON, J.R. (1981). Cross-Equatorial Response to Middle-Latitude Forcing in a Zonally Varying Basic State. Journal of the Atmospheric Sciences. 39, 722-733.

WALLACE, J.M e GUTZLER, D.S. (1981).Telecconections in the geopotential height field during the Northern Hemisphere winter. Mon.Weath. Rev. 109, 785-812.

WYRTKI, K. (1975). El Niño dynamic response of the equatorial Pacific Ocean to atmospheric forcing. J. Phys. Oceanogr., 5, 572-584.

WYRTKI, K. (1979). Response of sea surface topography to the 1976 El Niño.J. Phys. Oceanogr., 9, 1223-1231. 